OPEN ACCESS

Edited by:

Yi-Cheng Sun,

Institute of Pathogen Biology (CAMS),

China

Reviewed by: Mahesh Shanker Dhar National Centre for Disease Control,

Huaiqi Jing

Chinese Center for Disease Control and Prevention (China $C D C$ ), China

Katarzyna Brzostek,

University of Warsaw, Poland

*Correspondence:

Chenyang $L$

chenyang.li@fu-berlin.de

Specialty section:

This article was submitted to

Food Microbiology,

a section of the journa

Frontiers in Microbiology

Received: 25 August 2019 Accepted: 17 December 2019

Published: 23 January 2020

Citation:

Li C, Murugaiyan J, Thomas C, Alter $T$ and Riedel C (2020) Isolate

Specific Cold Response of Yersinia enterocolitica in Transcriptional,

Proteomic, and Membrane

Physiological Changes.

Front. Microbiol. 10:3037.

doi: 10.3389/fmicb.2019.03037

\section{Isolate Specific Cold Response of Yersinia enterocolitica in Transcriptional, Proteomic, and Membrane Physiological Changes}

\author{
Chenyang Lit*, Jayaseelan Murugaiyan ${ }^{2,3}$, Christian Thomas ${ }^{4}$, Thomas Alter ${ }^{1}$ and \\ Carolin Riedel ${ }^{1}$
}

1 Institute of Food Safety and Food Hygiene, Department of Veterinary Medicine, Freie Universität Berlin, Berlin, Germany, ${ }^{2}$ Institute for Animal Hygiene and Environmental Health, Department of Veterinary Medicine, Freie Universität Berlin, Berlin, Germany, ${ }^{3}$ Department of Biotechnology, SRM University AP, Amaravati, India, ${ }^{4}$ Department of Food Science and Technology, Beuth University of Applied Sciences Berlin, Berlin, Germany

Yersinia enterocolitica, a zoonotic foodborne pathogen, is able to withstand low temperatures. This psychrotrophic ability allows it to multiply in food stored in refrigerators. However, little is known about the $Y$. enterocolitica cold response. In this study, isolate-specific behavior at $4^{\circ} \mathrm{C}$ was demonstrated and the cold response was investigated by examining changes in phenotype, gene expression, and the proteome. Altered expression of cold-responsive genes showed that the ability to survive at low temperature depends on the capacity to acclimate and adapt to cold stress. This cold acclimation at the transcriptional level involves the transient induction and effective repression of cold-shock protein (Csp) genes. Moreover, the resumption of expression of genes encoding other non-Csp is essential during prolonged adaptation. Based on proteomic analyses, the predominant functional categories of cold-responsive proteins are associated with protein synthesis, cell membrane structure, and cell motility. In addition, changes in membrane fluidity and motility were shown to be important in the cold response of $Y$. enterocolitica. Isolate-specific differences in the transcription of membrane fluidity- and motility-related genes provided evidence to classify strains within a spectrum of cold response. The combination of different approaches has permitted the systematic description of the $Y$. enterocolitica cold response and gives a better understanding of the physiological processes underlying this phenomenon.

Keywords: Yersinia enterocolitica, cold response, proteome, isolates specific, motility, fluidity

\section{INTRODUCTION}

Yersinia enterocolitica, the third most commonly reported foodborne zoonotic pathogen in the European Union, can cause serious diseases, including gastroenteritis, mesenteric lymphadenitis, reactive arthritis, erythema nodosum, and pseudoappendicitis (Ostroff et al., 1994; Horisaka et al., 2004; European Food Safety Authority and European Centre for Disease Prevention and Control, 2016). It occurs ubiquitously in the natural environment and is widespread in animal populations (Benembarek, 1994; Robins-Browne, 2013). Furthermore, it can be isolated frequently 
from a variety of foods, including milk and milk products, pork, poultry, eggs, and produce (Bari et al., 2011).

Yersinia enterocolitica is capable of growing at temperatures approaching and even below $0^{\circ} \mathrm{C}$ (Tudor et al., 2008; Divya and Varadaraj, 2013). Therefore, even refrigeration temperatures (0$4^{\circ} \mathrm{C}$ ) can allow significant bacterial growth over time. Several studies have reported growth of $Y$. enterocolitica in food products stored at refrigeration temperatures: e.g., on raw beef, with increased cell counts of up to $2 \log \mathrm{CFU} / \mathrm{ml}$ within 4 days (Tudor et al., 2008) and in pasteurized milk, reaching levels of 5-7 log $\mathrm{CFU} / \mathrm{ml}$ after 7 days (with an initial inoculum of $1-3 \log \mathrm{CFU} / \mathrm{ml}$ ) (Amin and Draughon, 1987).

One of the most prominent cold responses is the induction of cold-shock proteins (Csps) in all psychrotrophs, mesophiles, and thermophiles (Polissi et al., 2003; Phadtare, 2004). As model systems, Escherichia coli and Bacillus subtilis have been studied in detail regarding cold response and Csps (Phadtare et al., 1999; Ermolenko and Makhatadze, 2002; Weber and Marahiel, 2003). The role of polynucleotide phosphorylase (PNPase, encoded by the pnp gene) in regulating cold response is also well described (Goverde et al., 1998; Yamanaka and Inouye, 2001; Cordin et al., 2006; Matos et al., 2009; Phadtare, 2011). This enzyme with the 3'- to 5'-exonucleolytic activities involved mostly in mRNA decay and ribosomes release (Coburn and Mackie, 1998; Polissi et al., 2003) is used to help repress the generation of Csps and relieve growth arrest (Neuhaus et al., 2003; Zhao et al., 2016). Meanwhile, in psychrotrophic bacteria such as Arthrobacter globiformis and Pseudomonas fragi, some cold-responsive proteins are synthesized at relatively moderate levels and prolonged in response to continuous growth at low temperatures (Berger et al., 1996; Michel et al., 1997). These proteins are of particular importance since they differentiate psychrotrophs from mesophiles, and they are probably one of the key determinants that allow survival at low temperature (Hébraud and Potier, 1999). Additionally, the ability to cope with temperature downshift must be accompanied by a number of changes in response to alterations of physical and biochemical parameters, including solubility, membrane fluidity, protein conformation and stability, and changes in gene expression (Hébraud and Potier, 1999; Vorachek-Warren et al., 2002; Albanesi et al., 2004; Phadtare, 2004; Cao-Hoang et al., 2010; Barria et al., 2013). Therefore, the biochemical and physiological effects allowing bacteria to adapt to temperature changes are likely to be complex, involving a number of cellular processes.

As a psychrotrophic bacterium, $Y$. enterocolitica has two well reported $\operatorname{csp}$ homolog genes $(\operatorname{csp} A$ and $\operatorname{csp} B)$, which are strongly expressed during the cold response. The cold-shock exoribonuclease PNPase and pnp gene have also been reported (Goverde et al., 1998; Phadtare, 2011). Additionally, a previous study has reported that genes involved in various functions (regulation, motility, virulence, and metabolism) are upregulated after a temperature downshift from optimal $\left(30^{\circ} \mathrm{C}\right)$ to suboptimal $\left(10^{\circ} \mathrm{C}\right)$ conditions in Y. enterocolitica (Bresolin et al., 2006). However, the effects of these genes and the cold response on protein expressional levels are not clarified in Y. enterocolitica.

Recently, advances in proteomics and bioinformatics technologies provide clear information on protein expression in response to cold and other stresses. High-throughput comparative proteomics with label-free quantification enabled the parsing of various potential mechanisms and regulatory networks of stress response in E. coli, B. subtilis, Pseudomonas putida, and Yersinia ruckeri (Delumeau et al., 2011; Stefanopoulou et al., 2011; Herbst et al., 2015; Kumar et al., 2016).

However, to our knowledge, the global proteomic profiles of $Y$. enterocolitica under the influence of low temperature have not been reported. Considerable research on Y. enterocolitica cold response has been limited to few proteins or genes and to single time points. The aim of this study is to describe the physiological processes of cold response in Y. enterocolitica via comparisons of growth ability, expression of cold-responsive genes and proteins, as well as cell motility and membrane fluidity of selected strains upon exposure to cold conditions.

\section{MATERIALS AND METHODS}

\section{Growth Profile at Low Temperature}

In order to test the growth ability of $Y$. enterocolitica at low temperatures $\left(4^{\circ} \mathrm{C}\right), 55$ isolates were collected from different matrices, representing different serotypes and biotypes (details are given in Table 1). Isolates were incubated on Plate Count agar (PC agar, Merck, Darmstadt, Germany) at $28^{\circ} \mathrm{C}$ for $24 \mathrm{~h}$. Single colonies were transferred to $3 \mathrm{ml}$ of Brucella broth (BB, BD Franklin Lakes, NJ, United States) and incubated at $28^{\circ} \mathrm{C}$ for $20 \mathrm{~h}$. Enriched cultures were serially diluted $1: 10^{6}$ in $\mathrm{BB}$ to reach a cell concentration of about $10^{1}-10^{2} \mathrm{CFU} / \mathrm{ml}$ as the initial value. Growth abilities of 55 strains were tested based on cell concentration in $\mathrm{BB}$ after incubating at $4^{\circ} \mathrm{C}$ for $168 \mathrm{~h}$. For growth profile investigation, cell concentration of the selected isolates (II7D, 8081, and 44B) was measured under cold stress for $0,24,48,72,144$, and $168 \mathrm{~h}$ respectively. The experiment was carried out in six biological replicates (with two technical duplicates each).

\section{RNA Extraction Under Cold Stress}

Yersinia enterocolitica isolates were selected for RNA extraction. Pre-culture was prepared in $12 \mathrm{ml} \mathrm{BB}$ at $28^{\circ} \mathrm{C}$ (as incubation temperature) for $24 \mathrm{~h}$. The suspension was diluted in $\mathrm{BB}$ to $0.05 \mathrm{OD}_{600}$ value and then incubated at $28^{\circ} \mathrm{C}$ for $2 \mathrm{~h}$ to reach an $\mathrm{OD}_{600}$ value between 0.1 and 0.2 . After centrifugation, the bacteria were suspended into $10 \mathrm{ml}$ cooled $\mathrm{BB}$ and incubated at $4^{\circ} \mathrm{C}$ for different time periods $(5 \mathrm{~min}, 30 \mathrm{~min}, 2 \mathrm{~h}, 4 \mathrm{~h}, 24 \mathrm{~h}$, and $48 \mathrm{~h}$ ). The pellet suspended in BB at room temperature was used as control. Cold-shock stop mix solution (5\% Roti-Aquaphenol, 95\% ethanol, Carl Roth, Karlsruhe, Germany) was added and samples were processed as described elsewhere (Blomberg et al., 1990). All samples were frozen at $-80^{\circ} \mathrm{C}$ until further use.

RNA was extracted with Roti-Aqua-Phenol (Carl Roth). RNA quality of samples was tested by gel electrophoresis. The ratio of absorbance $A_{260} / A_{280}$ and $A_{260} / A_{230}$ were used to assess the purity of RNA photometrically with NanoDrop ${ }^{\mathrm{TM}}$ 2000/2000c Spectrophotometers (Thermo Fisher Scientific). A ratio of $\sim 2.0$ is generally accepted of $A_{260} / A_{280}$ and the expected $A_{260} / A_{230}$ values are set in the range of 2.0-2.2. Reverse transcription 
TABLE 1 | Characteristics and growth ability of $Y$. enterocolitica strains at $4^{\circ} \mathrm{C}$ for $168 \mathrm{~h}$.

\begin{tabular}{|c|c|c|c|c|c|}
\hline Isolates & Median & Median norm. & Serotype & Biotype & Matrix \\
\hline 44B & $1.86 \mathrm{E}+03$ & $2.86 \mathrm{E}+02$ & $0: 5,27$ & $1 \mathrm{~A}$ & Food \\
\hline IP566/82 & $4.60 E+03$ & $8.85 E+02$ & O:8 & n. a. & n. a. \\
\hline 4780 & $5.90 E+05$ & $5.98 E+04$ & O:8 & $1 \mathrm{~B}$ & Human \\
\hline $96 / 10$ & $1.50 E+05$ & $1.01 E+05$ & $0: 8$ & $1 \mathrm{~B}$ & n. a. \\
\hline $39 / 91$ & $5.00 E+06$ & $2.87 E+05$ & O:8 & 1 & Human \\
\hline $21 / 08$ & $4.20 E+07$ & $3.41 E+06$ & $0: 8$ & $1 \mathrm{~A}$ & n. a. \\
\hline 8081 & $2.70 E+07$ & $6.85 E+06$ & O:8 & $1 \mathrm{~B}$ & Human \\
\hline $78 / 90$ & $1.07 E+08$ & $7.96 \mathrm{E}+06$ & $0: 8$ & $1 \mathrm{~B}$ & Human \\
\hline $25 \mathrm{la}$ & $1.25 E+08$ & $1.22 E+07$ & $0: 3$ & 4 & Food \\
\hline $96 \mathrm{~B}$ & $2.60 E+08$ & $2.23 E+07$ & $0: 5,27$ & 3 & Animal \\
\hline $177 \mathrm{~B}$ & $2.40 \mathrm{E}+08$ & $2.37 E+07$ & $0: 5,27$ & 2 & Human \\
\hline 207 Ila & $3.60 \mathrm{E}+08$ & $2.64 \mathrm{E}+07$ & $0: 9$ & 3 & Animal \\
\hline 207 la & $3.40 E+08$ & $3.56 \mathrm{E}+07$ & $0: 9$ & 3 & Animal \\
\hline $25 / 13$ & $8.10 E+08$ & $4.60 E+07$ & $0: 5$ & $1 \mathrm{~A}$ & Food \\
\hline $56 / 14$ & $5.90 E+08$ & $4.66 \mathrm{E}+07$ & $0: 5$ & $1 \mathrm{~A}$ & Food \\
\hline $57 / 14$ & $7.40 \mathrm{E}+08$ & $4.76 \mathrm{E}+07$ & $0: 9$ & 2 & Food \\
\hline $54 / 13$ & $6.45 E+08$ & $4.93 E+07$ & $0: 8$ & $1 \mathrm{~A}$ & Food \\
\hline $28 / 07$ & $1.00 E+09$ & $5.03 E+07$ & $0: 9$ & 3 & Animal \\
\hline $04 / 13$ & $4.90 E+08$ & $5.05 E+07$ & $0: 5$ & $1 \mathrm{~A}$ & Food \\
\hline $32 / 07$ & $4.30 E+08$ & $5.77 \mathrm{E}+07$ & $0: 3$ & 4 & Animal \\
\hline $05 / 13$ & $5.80 E+08$ & $5.79 E+07$ & $0: 5$ & $1 \mathrm{~A}$ & Food \\
\hline $44 / 07$ & $1.14 \mathrm{E}+09$ & $5.92 E+07$ & $0: 3$ & 4 & Food \\
\hline III15D & $7.00 E+08$ & $5.93 E+07$ & $0: 5$ & $1 \mathrm{~A}$ & Food \\
\hline $24 / 14$ & $4.50 E+08$ & $5.97 \mathrm{E}+07$ & $0: 5$ & $1 \mathrm{~A}$ & Food \\
\hline $29 / 07$ & $8.30 E+08$ & $5.99 E+07$ & $0: 9$ & 3 & Animal \\
\hline $09 / 11$ & 1.37E + 09 & $6.12 E+07$ & $0: 9$ & 2 & Food \\
\hline $37 / 12$ & $5.40 \mathrm{E}+08$ & $6.18 \mathrm{E}+07$ & $0: 5$ & $1 \mathrm{~A}$ & Food \\
\hline $65 / 14$ & $1.03 E+09$ & $6.29 \mathrm{E}+07$ & $0: 5$ & $1 \mathrm{~A}$ & Food \\
\hline $47 / 13$ & $5.50 E+08$ & $6.31 E+07$ & $0: 5$ & $1 \mathrm{~A}$ & Food \\
\hline $77 / 14$ & $6.40 \mathrm{E}+08$ & $6.46 \mathrm{E}+07$ & $0: 9$ & 2 & Food \\
\hline $115 \mathrm{C}$ & $6.80 E+08$ & $6.92 E+07$ & $0: 3$ & 3 & Animal \\
\hline 20/07 & $1.42 E+09$ & $7.17 \mathrm{E}+07$ & $0: 9$ & 3 & Human \\
\hline $11 / 07$ & $1.07 E+09$ & $7.32 \mathrm{E}+07$ & $0: 3$ & 4 & Human \\
\hline $38 / 12$ & $5.60 \mathrm{E}+08$ & $7.35 E+07$ & $0: 5$ & $1 \mathrm{~A}$ & Food \\
\hline $58 / 07$ & 1.13E + 09 & $7.73 \mathrm{E}+07$ & $0: 3$ & 4 & Animal \\
\hline $31 / 13$ & $7.60 \mathrm{E}+08$ & $7.86 \mathrm{E}+07$ & $0: 5,27$ & 2 & food \\
\hline $45 / 14$ & $1.21 E+09$ & $7.97 \mathrm{E}+07$ & $0: 5,27$ & 2 & Food \\
\hline 03/13 & $7.00 \mathrm{E}+08$ & $8.01 E+07$ & $0: 8$ & $1 \mathrm{~A}$ & Food \\
\hline 387/09 & $8.20 E+08$ & $8.06 \mathrm{E}+07$ & $0: 9$ & n. a. & Animal \\
\hline $06 / 13$ & $4.30 E+08$ & $8.36 \mathrm{E}+07$ & O:8 & $1 \mathrm{~B}$ & Food \\
\hline $18 / 07$ & $1.30 E+09$ & $8.45 E+07$ & 0:9 & 3 & Human \\
\hline $15 / 12$ & $9.40 E+08$ & $8.92 E+07$ & $0: 5,27$ & 2 & Food \\
\hline $19 / 07$ & $1.07 E+09$ & $9.62 E+07$ & $0: 3$ & 4 & Human \\
\hline $61 / 07$ & $1.12 E+09$ & $1.00 E+08$ & $0: 3$ & 4 & Animal \\
\hline $13 / 14$ & $1.12 E+09$ & $1.01 E+08$ & $0: 3$ & 4 & Food \\
\hline $12 / 07$ & $8.80 E+08$ & $1.02 E+08$ & $0: 3$ & 4 & Human \\
\hline $30 / 14$ & $9.50 E+08$ & $1.04 \mathrm{E}+08$ & $0: 5,27$ & 2 & Food \\
\hline 33/07 & $4.50 E+08$ & $1.09 E+08$ & $0: 3$ & 4 & Animal \\
\hline $25 / 14$ & $8.80 E+08$ & $1.12 \mathrm{E}+08$ & $0: 5,27$ & 2 & Food \\
\hline $11 / 09$ & $1.07 E+09$ & $1.14 \mathrm{E}+08$ & $0: 5,27$ & 2 & Food \\
\hline $14 / 07$ & $1.45 E+09$ & $1.15 E+08$ & $0: 3$ & 4 & Human \\
\hline $46 / 14$ & $1.56 \mathrm{E}+09$ & $1.21 \mathrm{E}+08$ & $0: 5,27$ & 2 & Food \\
\hline $89 / 14$ & $1.42 E+09$ & $1.27 E+08$ & $0: 3$ & 4 & Food \\
\hline $17 / 07$ & $9.70 E+08$ & $1.27 E+08$ & $0: 9$ & 3 & Human \\
\hline II7D & $1.02 E+09$ & $1.27 \mathrm{E}+08$ & $0: 5$ & $1 \mathrm{~A}$ & Food \\
\hline
\end{tabular}

Median norm.: relative median value normalized with the initial concentration, respectively. was performed with Maxima $\mathrm{H}$ Minus First Strand cDNA Synthesis Kit (Fermentas, St. Leon-Rot, Germany). The cDNA samples were diluted 1: 5 with nuclease-free water for RTqPCR investigation.

\section{Expressional Analysis of Cold-Responsive Genes}

Real-time quantitative PCR (RT-qPCR) was used to test the transcription level of cold-responsive genes of $Y$. enterocolitica. Eight genes, which were reported to have enhanced at transcriptional levels at $10^{\circ} \mathrm{C}$ (Bresolin et al., 2006), were tested in this study. These genes cover the functions of regulation, metabolism, and motility (Supplementary Table S2 lists target genes and used primers). The SsoFast EvaGreen Supermix (SYBR-green, Bio-Rad, Munich, Germany) was used for RTqPCR assays. The expression of the genes was normalized to the reference gene polA (DNA polymerase I) (Townsend et al., 2008). The results of RT-qPCR were visualized and evaluated by CFX software (Bio-Rad).

\section{Whole Cell Protein Extraction}

Three isolates (Y. enterocolitica strains II7D, 8081, and 44B) were subjected to incubation at $4^{\circ} \mathrm{C}$ for $0,5 \mathrm{~min}, 2 \mathrm{~h}$, and $24 \mathrm{~h}$. The cells were harvested and the pellet was washed with PBS. Cell pellets were reconstituted with $300 \mu \mathrm{l}$ distilled water and inactivated by addition of $900 \mu \mathrm{l}$ ethanol. After the centrifugation and evaporation, the final pellet was reconstituted with $250 \mu \mathrm{l} 20 \mathrm{mM}$ HEPES ( $\mathrm{pH}$ 7.4) and subjected to sonication for $1 \mathrm{~min}$ (cycle, 1.0; amplitude, 100\%) with a sonicator (UP100H; Hielscher Ultrasound Technology, Teltow, Germany). Supernatants were collected and the concentration was measured using modified Bradford's method with Coomassie Plus ${ }^{\mathrm{TM}}$ Protein Assays (Thermo Fisher Scientific, Rockford, IL, United States) and the samples were stored at $-20^{\circ} \mathrm{C}$ for further analysis. Each strain was tested six times independently.

\section{In-Solution Trypsin Digestion}

The in-solution trypsin digestion of proteins was performed as described previously (Wareth et al., 2016). Briefly, $10 \mu \mathrm{g}$ protein was used for acetone precipitation. The resultant peptides were then reconstituted with $20 \mu \mathrm{l}$ denaturation buffer containing $6 \mathrm{M}$ urea/2 $\mathrm{M}$ thiourea in $10 \mathrm{mM}$ HEPES $(\mathrm{pH}$ 8.0) and reduced with $10 \mathrm{mM}$ dithiothreitol in $50 \mathrm{mM}$ of ammonium bicarbonate (ABC, Sigma, Germany). The alkylation was carried out with $55 \mathrm{mM}$ iodacemtamide and subsequently $0.5 \mu \mathrm{g} / \mu \mathrm{l} \mathrm{LysC}$ solution was added. The urea concentration was decreased by $0.5 \mu \mathrm{g} / \mu \mathrm{l}$ trypsin and the trypsin digestion was stopped by $5 \%$ acetonitrile/3\% trifluoroacetic acid.

\section{Liquid Chromatography-Electrospray Ionization-Tandem Mass Spectrometry (LC-ESI-MS/MS) Measurements}

Liquid chromatography-electrospray ionization-mass spectrometry (LC-ESI-MS/MS) measurements were carried out as described elsewhere (Wareth et al., 2016). Resultant peptides of trypsin digestion were desalted by solid phase extraction and the peptides were separated using Dionex Ultimate 3000 
nanoLC (Dionex/Thermo Fisher Scientific, Idstein, Germany) on fritless silica micro-columns with an inner diameter of $100 \mu \mathrm{m}$. Mass spectrometry measurements were carried out using LTQ Orbitrap Velos mass spectrometer (Thermo Fisher Scientific, Bremen, Germany). The LTQ-Orbitrap was operated in the positive mode to simultaneously measure full scan MS spectra in the range of $m / z 300-1700$ in the Orbitrap analyzer at a resolution of $R=60,000$. After that, isolation and fragmentation of the 20 most intense ions in the LTQ part were carried out by collision-induced dissociation.

The raw mass spectra were processed using label-free quantification algorithm of the MaxQuant version 1.3.0.5 (Max Planck Institute of Biochemistry, Martinsried, Germany) (Tyanova et al., 2016) and protein identification was carried out by searching against protein sequence FASTA file of Y. enterocolitica strain YE02/02 (Proteome ID: UP000069750, protein count: 4760) with a wide range of homologous strains downloaded from UniProt database. The following parameters were set for protein identification: Initial maximum precursor $-7 \mathrm{ppm}$, fragment mass deviations $-0.5 \mathrm{Da}$; variable modification-methionine oxidation/acetylation of peptide N-termini; fixed modification-carbamidomethylation; enzymes-LysC and trypsin, both with a maximum of two missed cleavages; minimum peptide length-seven amino acids, and target-decoy-based false discovery rate (FDR) for peptide and protein identification- $1 \%$.

The statistical analysis was performed using the Perseus software version 1.4.1.3 (Max Planck Institute of Biochemistry, Martinsried, Germany) (Rudolph and Cox, 2019). The LFQ intensities of proteins were imported and transformed to logarithmic scale with base two. The Student's $t$-test and Benjamini-Hochberg procedure FDR corrections of the significant $p$-values $(p<0.05)$ were applied for identification of differentially expressed proteins.

\section{Motility Assay}

Motility was tested as described for Y. enterocolitica (Bresolin et al., 2008). Three strains II7D, 8081, and 44B were assessed by measuring diameters of migration zone at $4{ }^{\circ} \mathrm{C}$ with motility agar plates $(0.3 \%$ agar, $0.5 \% \mathrm{NaCl}$, and $1 \%$ tryptone). Strains were incubated on PC agar plates overnight at $28^{\circ} \mathrm{C}$. Single colonies were transferred onto motility agar plates and incubated initially at $37^{\circ} \mathrm{C}$ for $2 \mathrm{~h}$ to start the assay with non-motile bacteria. Plates were subsequently incubated at $28^{\circ} \mathrm{C}$ (for $21 \mathrm{~h}$ ) and $4^{\circ} \mathrm{C}$ (for $44 \mathrm{~h}$ ).

\section{Fluidity Assay}

Membrane fluidity of $Y$. enterocolitica was measured by a fluorescence polarization or anisotropy value, which corresponds to the reaction to polarized light of a fluorescent probe inside the membrane (Zaritsky et al., 1985; Aricha et al., 2004; Mykytczuk et al., 2007). Briefly, three isolates (Y. enterocolitica strains II7D, 8081 , and $44 \mathrm{~B}$ ) were prepared and incubated at $4^{\circ} \mathrm{C}$ for $0,2,24$, and $48 \mathrm{~h}$ with the method described above. Cultured cells were harvested and washed twice with PBS (10 mM, pH 7.4, Merck) and then incubated with $5 \mu \mathrm{M}$ 1,6-diphenyl-1,3,5-hexatriene (DPH, Sigma-Aldrich, St. Louis, MO, United States) at $37^{\circ} \mathrm{C}$ for $1 \mathrm{~h}$. Unlabeled cells were used as a scattering reference. The fluorescence polarization was measured using a Cary Eclipse Fluorescence spectrophotometer with Manual Polarizer (Agilent, Santa Clara, CA, United States) at $360 \mathrm{~nm}$ excitation and $430 \mathrm{~nm}$ emission. Fluorescence anisotropy was calculated by the formula $\mathrm{A}=\left[\mathrm{I}_{\mathrm{VV}}-\mathrm{I}_{\mathrm{VH}}\left(\mathrm{I}_{\mathrm{HV}} / \mathrm{I}_{\mathrm{HH}}\right)\right] /\left[\mathrm{I}_{\mathrm{VV}}+2 \mathrm{I}_{\mathrm{VH}}\left(\mathrm{I}_{\mathrm{HV}} / \mathrm{I}_{\mathrm{HH}}\right)\right]$, where $\mathrm{I}$ is the corrected fluorescence intensity, and the subscripts $\mathrm{V}$ and $\mathrm{H}$ indicate the values obtained with vertical or horizontal orientations, respectively. The emission polarized filter was set either in the vertical $\left(\mathrm{I}_{\mathrm{VV}}\right)$ or horizontal $\left(\mathrm{I}_{\mathrm{VH}}\right)$ position. Decrease in fluorescence anisotropy reflected increases in the fluidity of the lipid bilayer, which controls or alters the mobility of DPH in the membrane.

\section{Bioinformatics and Statistical Analysis}

Cell counts of the growth assays were expressed as the median with range for all the isolates $(\mathrm{CFU} / \mathrm{ml})$ and other quantitative data were expressed as the mean with the standard error of the mean. Paired sample $t$-tests were applied to determine differences in growth profile, gene expression, and fluidity. GraphPad Prism 6 was used to carry out the analyses cited above.

The Gene Ontology (GO) database ${ }^{1}$ and the Kyoto Encyclopedia of Genes and Genomes (KEGG) database ${ }^{2}$ were used to classify proteins and related pathways of proteins (Kanehisa et al., 2016). The Clusters of Orthologous Groups (COGs) functional categories of differentially expressed proteins were assigned by BLAST and searched with the COG database $^{3}$ referring to other research (Tatusov et al., 2001; Galperin et al., 2014).

\section{RESULTS AND DISCUSSION}

\section{Growth Profiles of Isolates at Low Temperatures}

Altogether, 55 isolates of $Y$. enterocolitica collected from food, humans, and animals were tested for their growth profiles at $4^{\circ} \mathrm{C}$ after $168 \mathrm{~h}$ (end-point analysis). Diverse growth abilities at $4^{\circ} \mathrm{C}$ among the isolates were observed. Most of the isolates displayed enhanced growth rates at $4^{\circ} \mathrm{C}$ over $168 \mathrm{~h}$, up to $10^{8} \mathrm{CFU} / \mathrm{ml}$ $(23.63 \%)$ and $10^{7} \mathrm{CFU} / \mathrm{ml}(61.81 \%)$, while a minority of strains (14.6\%) showed a slighter increase, up to $10^{2}-10^{6} \mathrm{CFU} / \mathrm{ml}$ (Table 1). More than $85 \%$ of tested strains exhibited enhanced growth rates, which indicated a general survival and growth ability of $Y$. enterocolitica at low temperatures. This result is consistent with the observations of high levels of this bacterium in food products; e.g., meat, milk, cheese, and oysters (Peixotto et al., 1979; Greenwood et al., 1985; Amin and Draughon, 1987; Wang et al., 2009), and natural environmental conditions; e.g., soil and aqueous at low temperature (Asadishad et al., 2013). However, significant differences in growth ability among the tested isolates were observed at $4^{\circ} \mathrm{C}$, which demonstrates the growth specificity of isolates at low temperature. Similar

\footnotetext{
${ }^{1}$ http://www.geneontology.org

${ }^{2}$ http://www.genome.jp/kegg/pathway.html

${ }^{3}$ http://www.ncbi.nlm.nih.gov/COG/
} 
observations (specific behavior of strains under low temperature) were found in Y. enterocolitica previously. For example, strains with various serotypes survived differently at $4^{\circ} \mathrm{C}$ in soil and river water (Tashiro et al., 1991). The impact of low temperatures on the survival of $Y$. enterocolitica strains differs when inoculated on raw pork samples at 4 and $-20^{\circ} \mathrm{C}$ for 90 days (Iliev and Najdenski, 2008).

To investigate the cold response of $Y$. enterocolitica, three isolates [44B (1A/O:5,27), 8081 (1B/O:8), and II7D (1A/O:5)] representing low, medium, and high growth ability at $4^{\circ} \mathrm{C}$, respectively, were selected for further analysis (Supplementary Table S1).

\section{Transcriptional Changes of Cold-Responsive Genes at Low Temperature}

In order to better understand the cold response in $Y$. enterocolitica, the correlation between growth ability and transcriptional changes was investigated in the three isolates. It has been mentioned that pnp gene played an indispensable role in the cold response of Y. enterocolitica (Goverde et al., 1998) and other bacteria (Mathy et al., 2001; Hu et al., 2014; Briani et al., 2016). In our study, during a cold response, an increased expression of $p n p$ gene was detected (Figure 1A). When exposed to $4^{\circ} \mathrm{C}$ for $5 \mathrm{~min}$ to $2 \mathrm{~h}$, the $p n p$ expression of the three isolates exhibited no significant difference. After $4 \mathrm{~h}$ of exposure at $4^{\circ} \mathrm{C}$, the expression of $p n p$ in $44 \mathrm{~B}$ increased continuously and significantly exceeded that of II7D and 8081 . The results indicated that different changes of $p n p$ expression were found among tested isolates with various growth ability, which verified the essentiality of the pnp gene in cold adaptation. The continuous high expression of $p n p$ gene implies the higher demand of PNPase and pnp in 44B.

Based on the role of PNPase (encoded by the pnp gene) in repressing the generation of Csps and relieving growth arrest (Neuhaus et al., 2003; Zhao et al., 2016), the changes in related genes were investigated. RT-qPCR was performed with eight genes, which were reported to have increasing peaks or steady enhancement in gene expression after temperature downshift (Bresolin et al., 2006). The RNA used for this analysis was extracted from isolate cultures kept at $4^{\circ} \mathrm{C}$ from $5 \mathrm{~min}$ to $48 \mathrm{~h}$ and the related genes in response to cold with various functions are listed in Supplementary Table S2 accordingly.

As Figure 1B shown, the expression of the genes $\operatorname{csp} A, \operatorname{csp} B$, $g l t P$, and $u h p C$ increased rapidly after a cold stimulation and then decreased over time, which is consistent with the result from previous study regarding changes of the cold-shock genes (Bresolin et al., 2006; Horn et al., 2007). Based on the expression of these cold-shock genes, the expression decreased rapidly in strains II7D and 8081 after the transcriptional peak. However, in strain $44 \mathrm{~B}$, the expression of these genes decreased slowly and the relative expression of $\operatorname{csp} B, g l t P$, and $u h p C$ was higher than that of II7D and 8081 at the end of $4 \mathrm{~h}$ after cold stress. Since the function of PNPase was RNA degradation and the higher expression of pnp was observed in 44B (Figure 1A), the repression of Csp generation might not be accomplished in 44B.
As reported previously, after the repression of Csp production, the growth reinitiated at the end of the acclimation phase (Yamanaka and Inouye, 2001). Therefore, the RNA degradation of Csps by PNPase was indispensable for cold acclimation and growth resumption. Similar cold acclimation was also found in E. coli, in which the synthesis of Csps transiently increases and the control of mRNA stability and translatability plays a major role in the adaptive response to cold temperature (Phadtare et al., 1999; Briani et al., 2016).

A different cold response was detected on transcriptional levels of YE1436, fleC, fliS, and YE2848, which did not show increased peaks but mostly increased under cold stress over prolonged growth. According to the expression of genes YE1436 and YE2848, the transcriptional levels increased over time and the upward tendencies in II7D and 8081 are more obvious than that in 44B (even no obvious uptrend of YE1436 gene expression). After $48 \mathrm{~h}$ of cold stress, the relative expression of YE1436 and YE2848 was significantly lower in 44B compared with II7D and 8081. Considering the worse growth ability of $44 \mathrm{~B}$ at low temperature, the transcriptional regulation of gene YE1436 and YE2848 might be necessary for cold response. As it was mentioned in other studies, one of the psychrotrophic abilities in bacteria was to produce several non-Csps and allow growth during prolonged low temperatures in cold adaptation (Berger et al., 1996; Hébraud and Potier, 1999; Wouters et al., 2000; Phadtare, 2004). After the cold acclimation, the expression of non-cold shock genes has not been resumed in 44B, arresting the transition from acclimation to cell growth.

In addition, after $48 \mathrm{~h}$ of cold stress, the expression of fle $\mathrm{C}$ and $f l i S$ genes increased in 44B while their expression did not increase until $24 \mathrm{~h}$ in II7D and 8081. Since the genes fle C and fliS are associated with bacterial motility, the regulation of motility might contribute to cold adaptation as well.

Consequently, the transcriptional changes in cold-responsive genes play an important role in both cold acclimation and prolonged adaptation. The isolate-specific ability to survive under cold stress depends on the capacity of enabling transient induction and effective repression of cold-shock gene in cold acclimation. Meanwhile, the resumption of the non-cold shock gene expression was also required in prolonged cold adaptation.

\section{Global Proteomic Analysis of the Cold-Responsive Proteins at Low Temperature}

Three isolates (II7D, 8081, and 44B) with various growth abilities were used for the proteomic analysis to further investigate the underlying processes of cold response. A total of 1526 proteins were identified using label-free quantification analysis in six biological replicates. Among these, 809 proteins which expressed differentially under cold stress (at 4 versus $28^{\circ} \mathrm{C}$ ) for $5 \mathrm{~min}, 2 \mathrm{~h}$, and $24 \mathrm{~h}$ in three strains were identified. Functional classification and annotation indicated that 715 and 790 uniproteins were assigned to $30 \mathrm{GO}$ annotations and 138 KEGG functional pathways, respectively.

The proteins assigned to GO functional groups were classified into three categories: "biological process," "molecular 


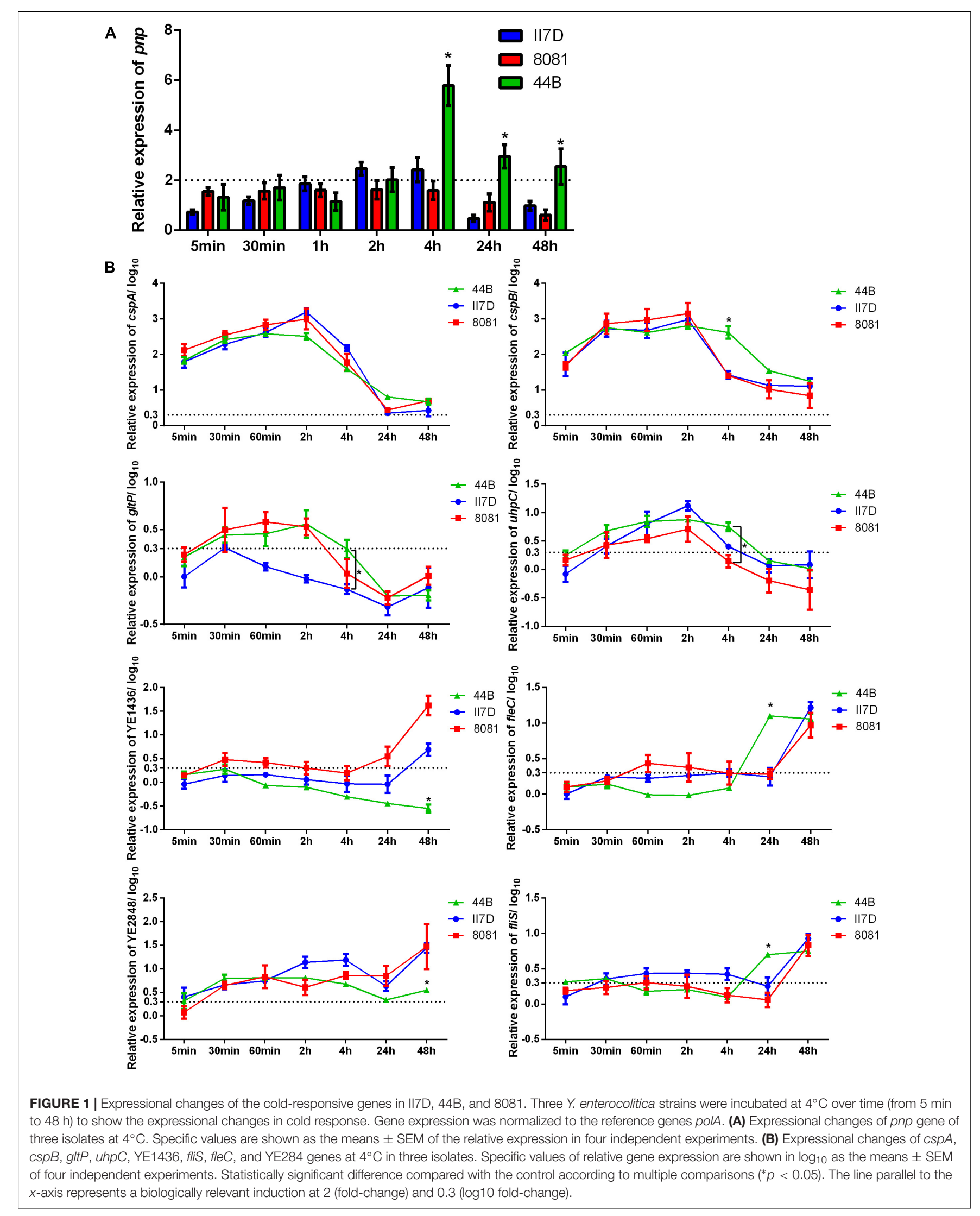


function," and "cellular component" (Figure 2). Various biological processes were involved in cold response. The most predominant processes were cellular and metabolic process; other major process categories were biological regulation, localization, and cellular component organization or biogenesis. These results indicated that the effects of cold response on protein level in $Y$. enterocolitica were involved in multiple processes. Furthermore, the predominant molecular functions of expressed proteins were associated with catalytic activity and binding; molecular functions of transporter and structural molecule activity were also involved in. Additionally, the most predominant cellular components were located cell and membrane parts. These results implied that the metabolism of the bacteria changed severely after cold response and it might lead to the alterations of cell and membrane components. Considerable groups of temperature-associated proteins were also reported previously in many other studies. For example, the periplasmic proteins associated with cellular component organization are strongly altered in Yersinia pestis in response to temperature changes (Pieper et al., 2008). The proteins involved in metabolic processes highly expressed at $4^{\circ} \mathrm{C}$ in Listeria monocytogenes (Cacace et al., 2010). During an abrupt temperature downshift in E. coli, expressional alterations occurred in the proteins associated with transport and binding (Kocharunchitt et al., 2014).

For further investigation, the KEGG database was used and the expressed proteins were identified in four categories: "metabolism," "genetic information processing," "environmental information processing," and "cellular processes" (Figure 3). It displayed that "Metabolism" with seven subcategories was the most enriched, which verified the active metabolic changes after a cold response. Among these subcategories, more proteins were enriched in metabolic related pathways: carbohydrate metabolism, nucleotide metabolism, amino acid biosynthesis, and translation. Similar pathways involved in cold response were also described in L. monocytogenes and E. coli (Cacace et al., 2010; Kocharunchitt et al., 2014).

\section{Analysis of Differentially Expressed Proteins at Low Temperature}

To investigate the alteration of metabolism related to growth profile under cold temperature over time, differentially expressed proteins were investigated at different time points in two isolates, $44 \mathrm{~B}$ and II7D (with low and high growth ability at $4^{\circ} \mathrm{C}$ ). Differentially expressed proteins of $44 \mathrm{~B}$ and II7D under cold stress for $2 \mathrm{~h}$ (early stage, T1) and $24 \mathrm{~h}$ (late stage, T2) were compared (Figure 4).

Differentially expressed proteins were classified into 20 COGs functional groups with a relative fold change $\left[\log _{2}\right.$ (FC) $>1.2$ and $\left.\log _{2}(\mathrm{FC})<-0.8, p<0.05\right]$. The expressed protein response to the early stage of the cold response (T1) was enriched into 17 functional clusters. Of these, the most predominant categories were "amino acid transport and metabolism," "translation, ribosomal structure, and biogenesis," "carbohydrate transport and metabolism," "cell motility," and also

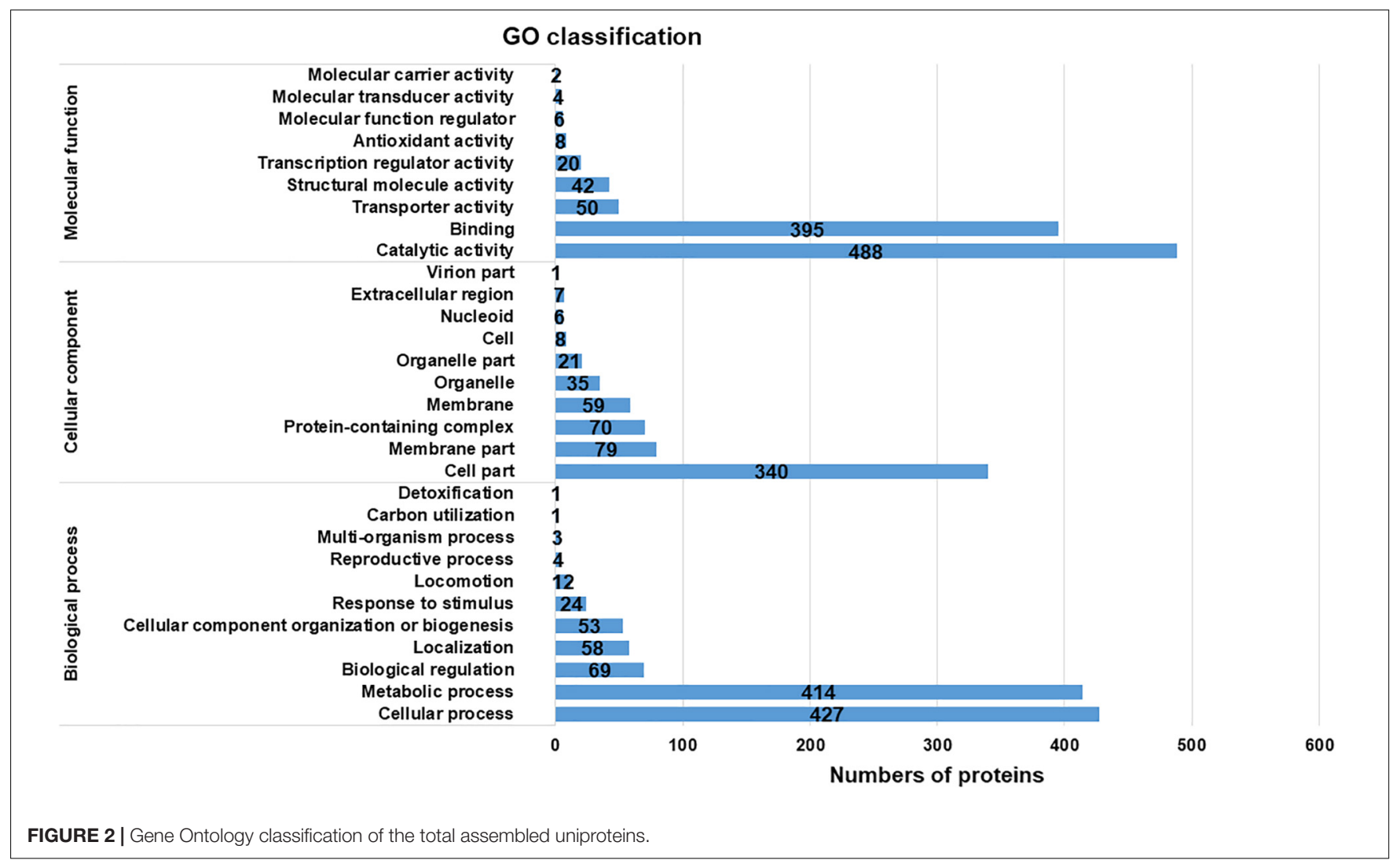




\section{KEGG classification}

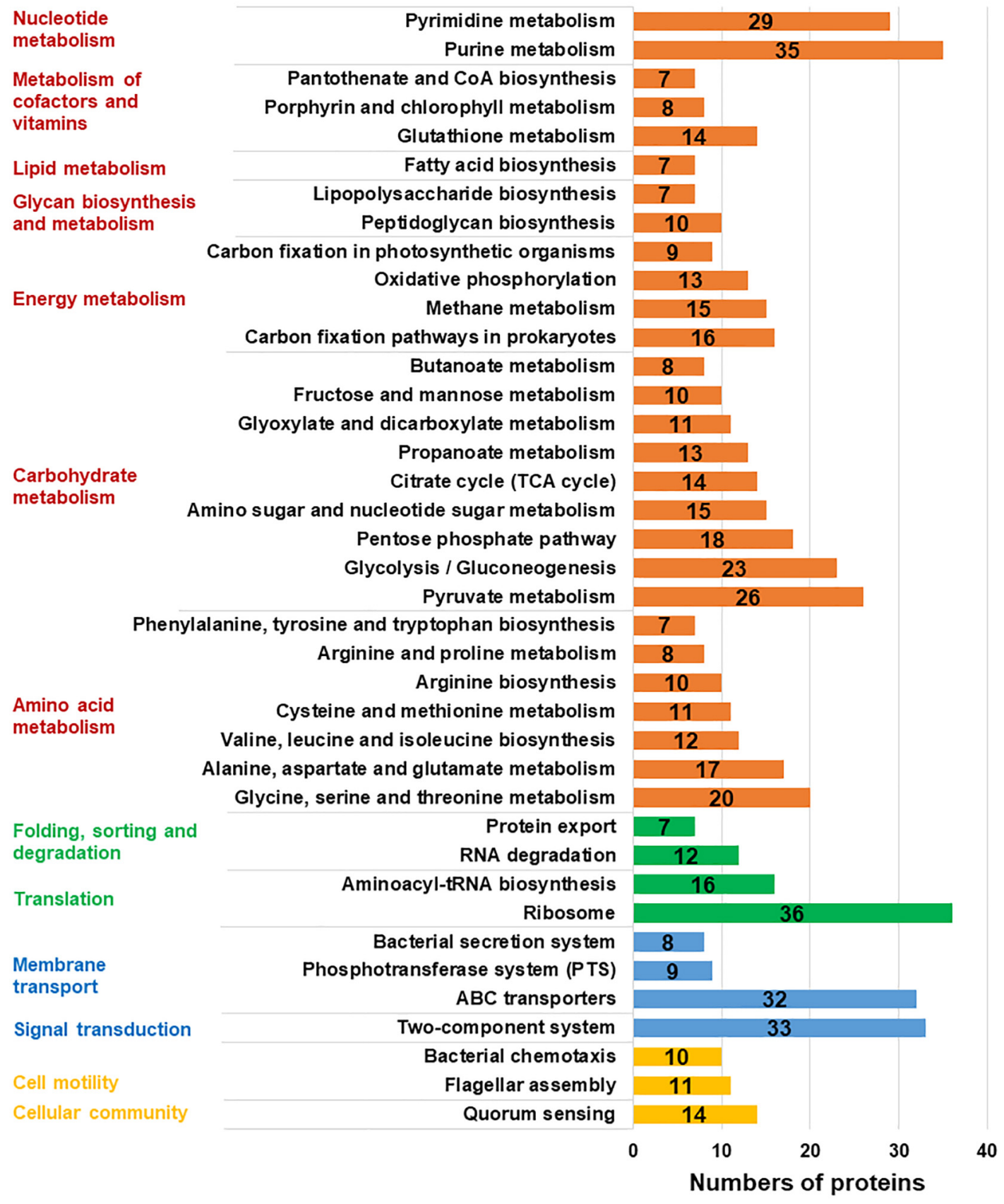

FIGURE 3 | KEGG pathway clusters of assembled uniproteins. Metabolic pathways in different functional groups involved in cold response were classified with KEGG database in four related categories (protein numbers of each group higher than 10): "metabolism" in red, "genetic information processing" in green, "environmental information processing" in blue, and the "cellular processes" in yellow. The subcategory titles were also represented.

"transcription." For the late stage of the cold response (T2), a high abundance of proteins was observed for categories of "amino acid transport and metabolism," "translation, ribosomal structure, and biogenesis," "cell wall/membrane/envelope biogenesis," and "carbohydrate transport and metabolism." In addition, a high abundance of the proteins belonging to "general function prediction only" was also found in both stages
(Figures 4A,B). Throughout the whole testing course (T1$\mathrm{T} 2$ ), proteins in specific functions of amino acid transport and metabolism (E), translation, ribosomal structure and biogenesis $(\mathrm{J})$, carbohydrate transport and metabolism $(\mathrm{G})$, and energy production and conversion $(\mathrm{C})$ had higher enrichment in both $\mathrm{T} 1$ and $\mathrm{T} 2$. Hence, the proteins are involved mostly in metabolism in response to cold. Similarly, the 


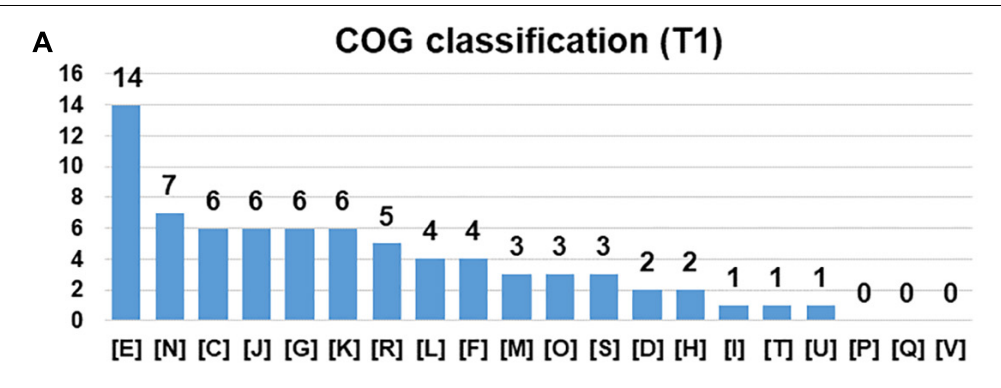

B

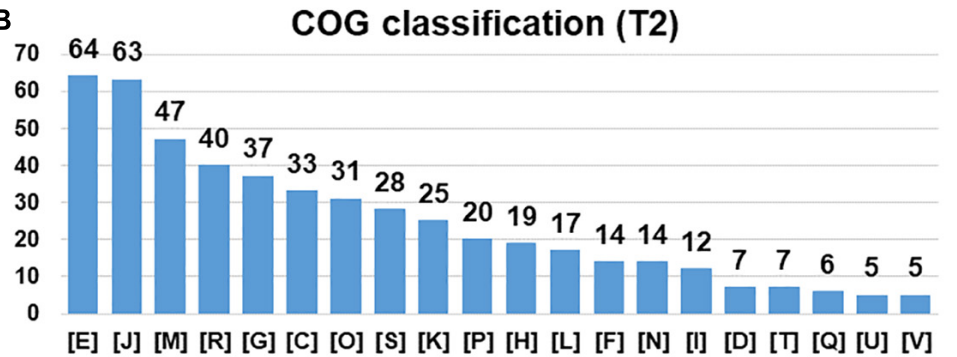

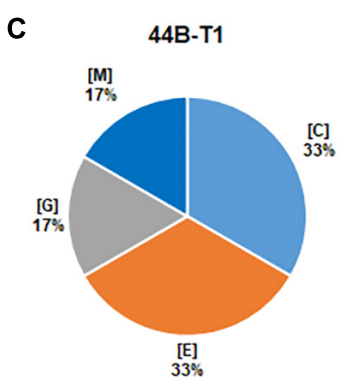
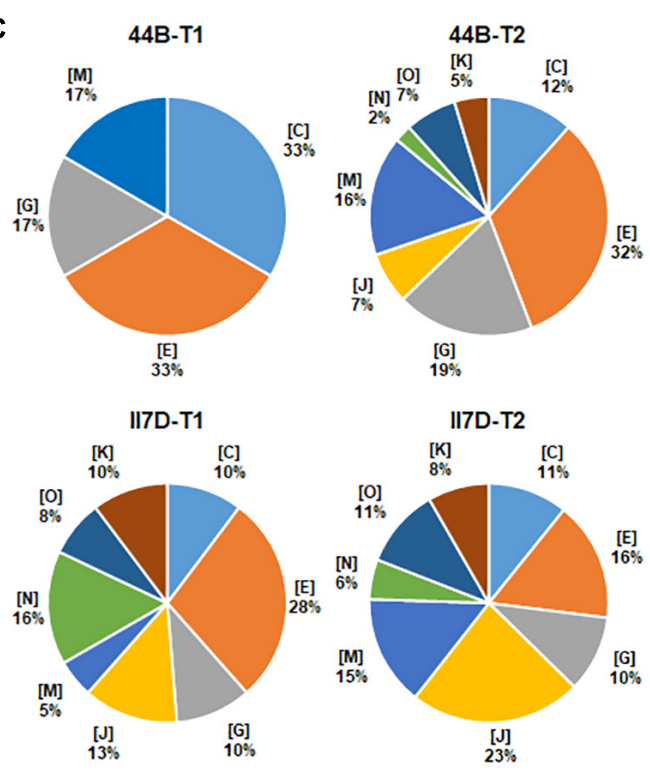

Numbers of proteins

FIGURE 4 | Functional category distribution of proteins identified from Y. enterocolitica cells at low temperature. (A) The number of identified proteins belong to each functional category is shown under cold stress after $2 \mathrm{~h}(\mathrm{~T} 1)$. (B) The number of identified proteins belong to each functional category is shown under cold stress after $24 \mathrm{~h}$ (T2). (C) The percentage of differential expressed proteins that belong to each functional category in II7D and 44B is shown under cold stress in two time (T1 and T2). COG categories are as follows: C: energy production and conversion; D: cell division and chromosome partitioning; E: amino acid transport and metabolism; F: nucleotide transport and metabolism; G: carbohydrate transport and metabolism; H: coenzyme metabolism; I: lipid metabolism; J: translation, ribosomal structure and biogenesis, K: transcription; L: DNA replication, recombination and repair; M: cell wall/membrane/envelope biogenesis; N: cell motility; O: post translational modification, protein turnover, chaperones; P: inorganic ion transport and metabolism; Q: secondary metabolites biosynthesis, transport and catabolism; R: general function prediction only; S: function unknown; T: signal transduction mechanisms; U: intracellular trafficking, secretion, and vesicular transport; V: defense mechanisms.

high abundances of proteins regarding metabolism-related pathways and metabolic process were also investigated in the KEGG and GO analysis. Hence, we assume that the major cold-responsive proteins participate in the metabolic regulation of cells.

However, differences in protein abundance were observed between T1 and T2. Especially, protein abundance existed mostly in the clusters of cell motility $(\mathrm{N})$ and transcription $(\mathrm{K})$ in T1 while cell wall/membrane/envelope biogenesis (M) and post-translational modification, protein turnover, chaperones (O) in T2. This result indicates that the effects of the cold response on protein levels differ in the early and late stages. The time-dependent differences in protein categories were also found in $E$. coli in response to temperature and water-activity changes and were closely related to the cultivability after the temperature downshift (King et al., 2016). Different phases including adaptation and re-growth phases could be divided based on clustering analyses. Additionally, various protein categories were involved such as energy metabolism, DNA repair system, amino acid biosynthetic pathways, and carbohydrate catabolism (King et al., 2016).

According to the COG classification, eight protein clusters with the most protein abundance in $\mathrm{T} 1$ or $\mathrm{T} 2$ were chosen to compare the differences between strain $44 \mathrm{~B}$ and II7D (Figure 4C). Compared with the protein abundance in the other three pie charts, protein clusters of $(\mathrm{K}),(\mathrm{O}),(\mathrm{J})$, and
(N) were undetectable in the early stage of $44 \mathrm{~B}$ (T1) and the proportions of these proteins in all selected proteins in $44 \mathrm{~B}$ (T2) were lower than those in II7D (T1) and II7D (T2). This result demonstrates that the biogenesis of responding proteins in 44B lags behind II7D under cold stress. Meanwhile, the proteins in clusters of $(\mathrm{K}),(\mathrm{O})$, and (J) represent key processes of protein biosynthesis. Hence, lower abundances of these proteins in 44B (T1) and 44B (T2) suggested that synthesis of general proteins might be inhibited in 44B compared to strain II7D. As was shown in many bacteria (e.g., E. coli), the arrest of cell growth upon temperature downshift is caused by the severe inhibition of general protein synthesis (Phadtare, 2004). The inhibition of general proteins in 44B (both in $\mathrm{T} 1$ and $\mathrm{T} 2$ ) might be the reason for low growth ability at low temperature. Considering the expressional repression of cold acclimation genes in $44 \mathrm{~B}$ (Figure 1B), the inhibition might be involved in synthesis of cold acclimation proteins, which are essential for cold adaptation during prolonged growth.

In addition, a lower abundance of protein cluster $(\mathrm{N})$ related to the "cell motility" was also mentioned in 44B. Base on the proteomic results, some cold-responsive proteins related to flagella and chemotaxis were detected in II7D but not in 44B (data not shown). For example, the Flg family, used for flagellar assembly and motility, are temperaturedependent in E. coli and other bacteria (Phadtare, 2012; 
Osterman et al., 2015). The chemotaxis protein, Che family is essential for motility and cold response (Burkart et al., 1998; Liu et al., 2014). According to the transcriptional analysis in Figure 1B, the correlation between motility and growth ability was demonstrated due to the different expressional changes of motility-related genes fle C (homologous to fliC and encoding Flagellin), fliS (putative cytoplasmic chaperone), and YE2848 (putative chemotaxis methyl-accepting transducer) in three isolates. Meanwhile, the Flagellin was detectable only in II7D but not in $44 \mathrm{~B}$ in proteomic analysis (other related genes were not found). Since it is critical in motility and cold response in Salmonella enterica (Elhadad et al., 2015; Michaux et al., 2017), the involvement of motility in cold response might be confirmed.

On the other hand, the percentages of clusters of energy production and conversion (C), carbohydrate transport and metabolism (G), and cell wall/membrane/envelope biogenesis (M) in 44B (T1) are higher than those in 44B (T2), II7D (T1), and II7D (T2). Considering the high abundance of proteins related to carbohydrate metabolism and cell wall/membrane/envelope biogenesis, but low enrichment of proteins related to functional protein synthesis in strain 44B (T1), we might assume that 44B uses a high rate of energy for the cell wall structure, instead of initial growth at cold response. As an important protective structure against adverse environmental conditions, the cell membrane plays an important role in stress response. Previously, it was extensively discussed that membrane lipopolysaccharide, cell membrane, and the membrane fluidity contribute to temperature adaptation in bacteria (Carty et al., 1999; Phadtare, 2004; Storz and Hengge, 2010).

\section{Motility at Low Temperature}

To investigate the physiological changes in cold response, motility assays at low temperatures were performed on three isolates (44B, 8081, and II7D) with different growth profiles at low temperatures. All three strains showed motility at $28^{\circ} \mathrm{C}$; however, at the temperature of $4^{\circ} \mathrm{C}$, only II7D was motile (Figure 5).

As shown in our transcriptional analysis, the expression of motility-related genes ( $f l i S$ and $f l e C$ ) increased under cold stress at $4^{\circ} \mathrm{C}$ and their expression was increased earlier in strain $44 \mathrm{~B}$ than in the other two strains (Figure 1B). Meanwhile, a lower abundance of proteins was present in the "cell motility" group in $44 \mathrm{~B}$, which was consistent with the lower growth ability in $44 \mathrm{~B}$ than II7D. Moreover, the differential growth ability correlates with motility in the three strains (only the strain with high growth ability was motile) at low temperature. Based on the results from transcriptional and proteomic analysis, the different induction of the motility-related genes and proteins among isolates with different growth behaviors indicated the close link between cell motility and growth ability, which has been described previously in Y. enterocolitica (Kapatral et al., 1996). However, due to the wide range of factors with complex mechanisms in regulating motility, how cell motility was affected by or contributed to the growth ability after cold response remains unclear (Young et al., 1999; Mukherjee et al., 2013; Xu et al., 2014).

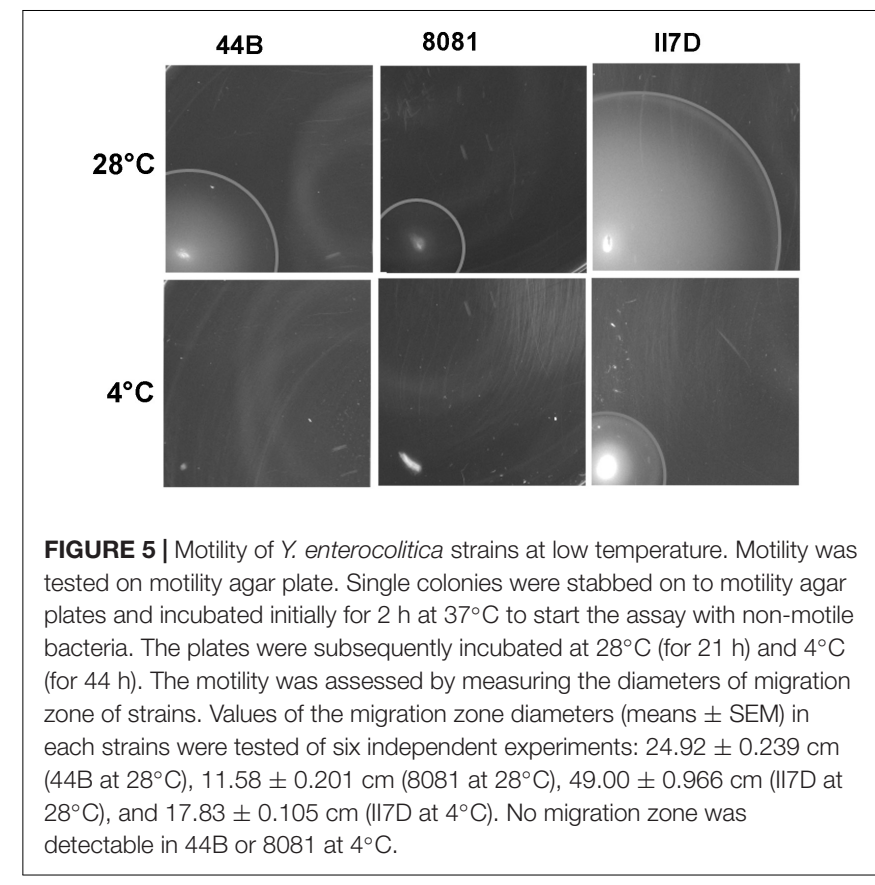

\section{Cell Membrane and Fluidity at Low Temperature}

To test other factors corresponding to membrane activity in cold response, fluidity assays were performed at $4^{\circ} \mathrm{C}$ on three isolates (44B, 8081, and II7D). All three tested strains showed stable fluidity under the temperature of $28^{\circ} \mathrm{C}$ in $48 \mathrm{~h}$, while the membrane fluidity of $44 \mathrm{~B}$ increased significantly at $4^{\circ} \mathrm{C}$ at $2 \mathrm{~h}$ and decreased to the normal level at $4^{\circ} \mathrm{C}$ after $24 \mathrm{~h}$ (Figure 6A). According to the results of fluidity, the membrane fluidity maintained at the normal level in both strains 8081 and II7D, but not in 44B. These results indicated that the balance of the membrane fluidity was changed in response to cold stress in $44 \mathrm{~B}$ at $2 \mathrm{~h}$. This finding might be correlated to the high protein abundance in the functional cluster of cell wall/membrane/envelope biogenesis in $44 \mathrm{~B}$ at $\mathrm{T} 1$. Therefore, the differences in growth abilities at low temperature might be related to the maintenance of cell fluidity. The similar roles of membrane fluidity have been demonstrated in cold and other stresses in many bacteria (Yoon et al., 2015; Eberlein et al., 2018). However, the fluidities are regulated by various mechanisms in different bacteria; e.g., E. coli (Carty et al., 1999), B. subtilis (Aguilar et al., 2001), and Salmonella (Wollenweber et al., 1983; Ricke et al., 2018).

To investigate the regulatory factors of membrane fluidity in $Y$. enterocolitica, groups of genes regarding outer membrane proteins and lipid A biosynthesis were selected according to previous studies (Dekker, 2000; Nikaido, 2003; Barria et al., 2013; Hussain and Bernstein, 2018; Robinson, 2019). Transcriptional changes in these genes were investigated under cold stress for $2 \mathrm{~h}$ in three isolates with the primers listed in Supplementary Table S3. In strain 44B, significantly higher expression of yaeT, $y f g L, d a p X$, and $p l d A$ and lower expression of $y f i O$ and $l p x P$ was observed compared to the other isolates (Figure 6B). The 

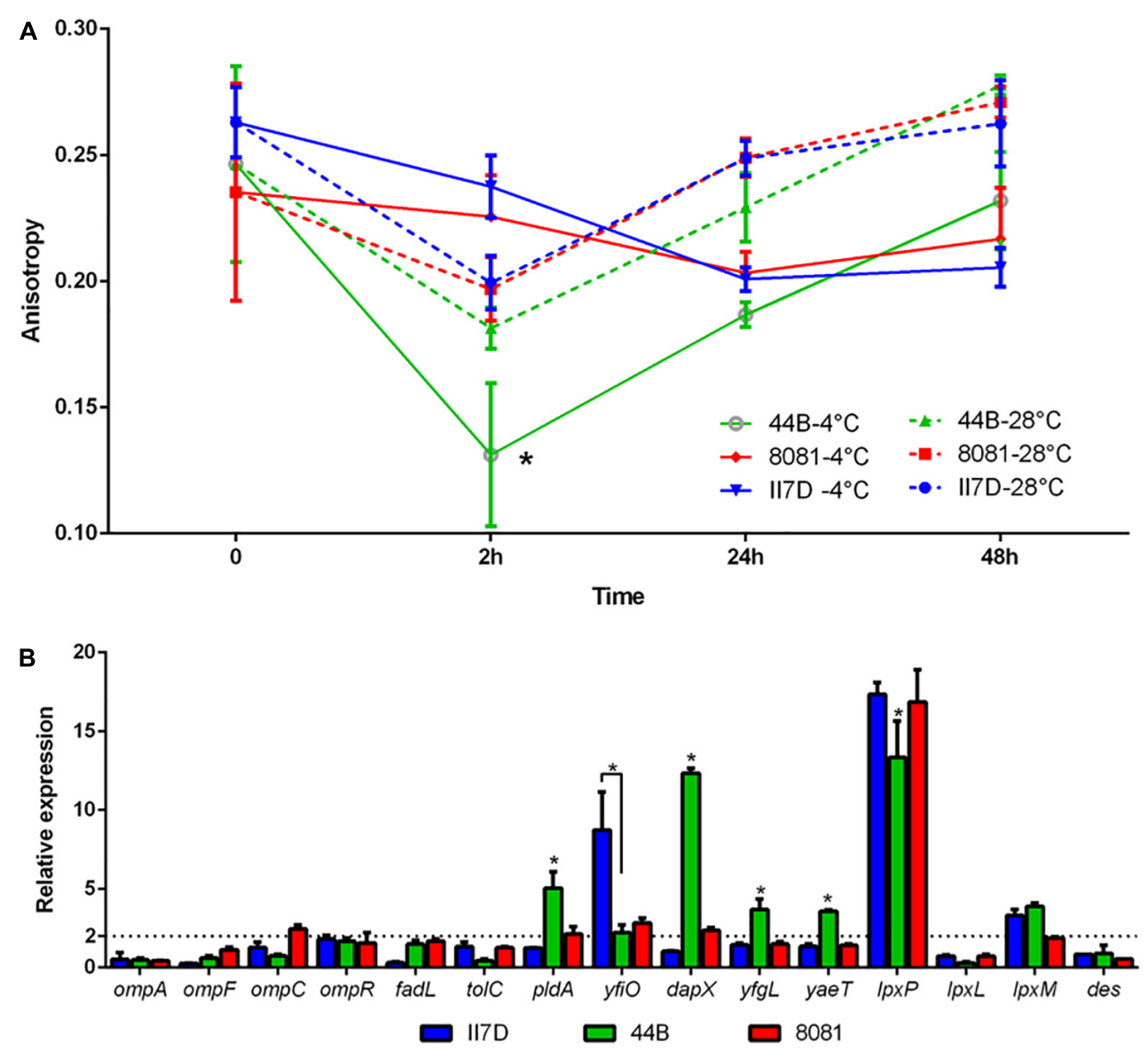

FIGURE 6 | Membrane fluidity and transcriptional changes of membrane-related genes in Y. enterocolitica strains at low temperature. (A) Fluidity assays in II7D, 44B, and 8081 under cold stress for 2, 24, and $48 \mathrm{~h}$. Anisotropy value represented the membrane fluidity (higher anisotropy means lower fluidity). (B) Expressional changes of the membrane related genes were detected using RT-qPCR and were normalized to the reference gene polA. Specific values of relative gene expression are shown as the means \pm SEM of four independent experiments. The line parallel to the $x$-axis represents a biologically relevant induction at 2 (fold-change). Statistically significant difference compared with the control according to multiple comparisons $\left({ }^{*} p<0.05\right)$.

four outer membrane protein assembly factors (encoded by yae $T$, $y f g L$, dap $X$, and $y f i O$ ) were found in proteomic analysis, in which, BamC encoded by dapX was upregulated significantly in 44B. The differential expression of these genes and proteins might be involved in fluidity regulation in response to cold. Similar functions of the outer membrane protein YaeT, DapX, and YfgL (homologous to insert $\beta$-barrel proteins in E. coli) were shown in previous research in response to cold (Macintyre and Henning, 1990; Onufryk et al., 2005; Wu et al., 2005; Begic and Worobec, 2006; Sklar et al., 2007; Rollauer et al., 2015). Outer membrane phospholipase A (encoded by pldA), which is activated under various stress conditions, presents in the outer membrane of Gram-negative bacteria. Its possible role is maintaining the cell envelope integrity and permeabilization, which is related to temperature (Dekker, 2000; Belosludtsev et al., 2014). The different expressions of pldA gene and protein among isolates suggested the possible involvement of outer membrane phospholipase A in fluidity maintenance under cold stress. However, their functions in cold response still remain to be elucidated in Y. enterocolitica.
Des and LpxP (encoded by des and lpxP genes) are two fluidity-generated enzymes in B. subtilis and E. coli. In B. subtilis, upon a drop in temperature, the Des protein is synthesized and desaturates the acyl chains of membrane phospholipids to increase the membrane fluidity (Aguilar et al., 2001; Albanesi et al., 2004). Furthermore, in E. coli, cold-induced acyltransferase LpxP helps to attach more unsaturated fatty acids (palmitoleate instead of laurate attached at normal temperature by LpxL) to lipid $\mathrm{A}$, thus increasing membrane fluidity and lowering its phase transition temperature, counteracting the effect of low temperature (Vorachek-Warren et al., 2002). In our study, no significant difference in the expression of des gene was observed among the three isolates and the Des protein did not induced, which implied that the regulation of Des in $Y$. enterocolitica might not be as important as that in B. subtilis. Meanwhile, expression of the cold induced gene lp $x P$ was significantly lower in $44 \mathrm{~B}$ and the related protein were induced differently between II7D and 44B according to proteomic analysis (Supplementary Table S4). Therefore, membrane fluidity related to growth ability in Y. enterocolitica 
might be regulated by LpxP in cold adaptation, which is identical to E. coli.

\section{Proteomic Overview of the Cold Response in Y. enterocolitica}

Cold response involved a series of complex and significant changes in the abundance of proteins in many processes and pathways rather than a simple increase or decrease in a specific category. To present an overview of the cold response of $Y$. enterocolitica, the upregulated proteins under cold stress were selected according to the main COG functional categories mentioned in this study. These particular proteins probably represented the key determinants that allow life at low temperature. Top KEGG pathways (including the BRITE hierarchies) were selected according to the proteins in COG categories (listed in Supplementary Table S4). Proteomic overview and the predicted regulation in cold response are presented in Figure 7.

First, a high abundance of proteins was observed associated with protein biosynthetic processes, such as transcriptional, translational, and ribosomal, and post-translational processes (related COG categories are shown in yellow boxes). These proteins were involved predominate in transcription factors, RNA degradation, peptidases and inhibitors, ribosome biogenesis, and aminoacyl-tRNA biosynthesis. Numbers of proteins related ribosome biogenesis [such as the transcription termination/anti-termination protein NusA, ribosomeassociated inhibitor A (encoded by raiA), and ribosomal RNA small subunit methyltransferase B (encoded by $r s m B$ )] were induced in response to cold. These related protein associated with cold stress was also reported in E. coli and other bacteria (Burakovsky et al., 2012; Di Pietro et al., 2013). Meanwhile, functions of the proteins induced in this study

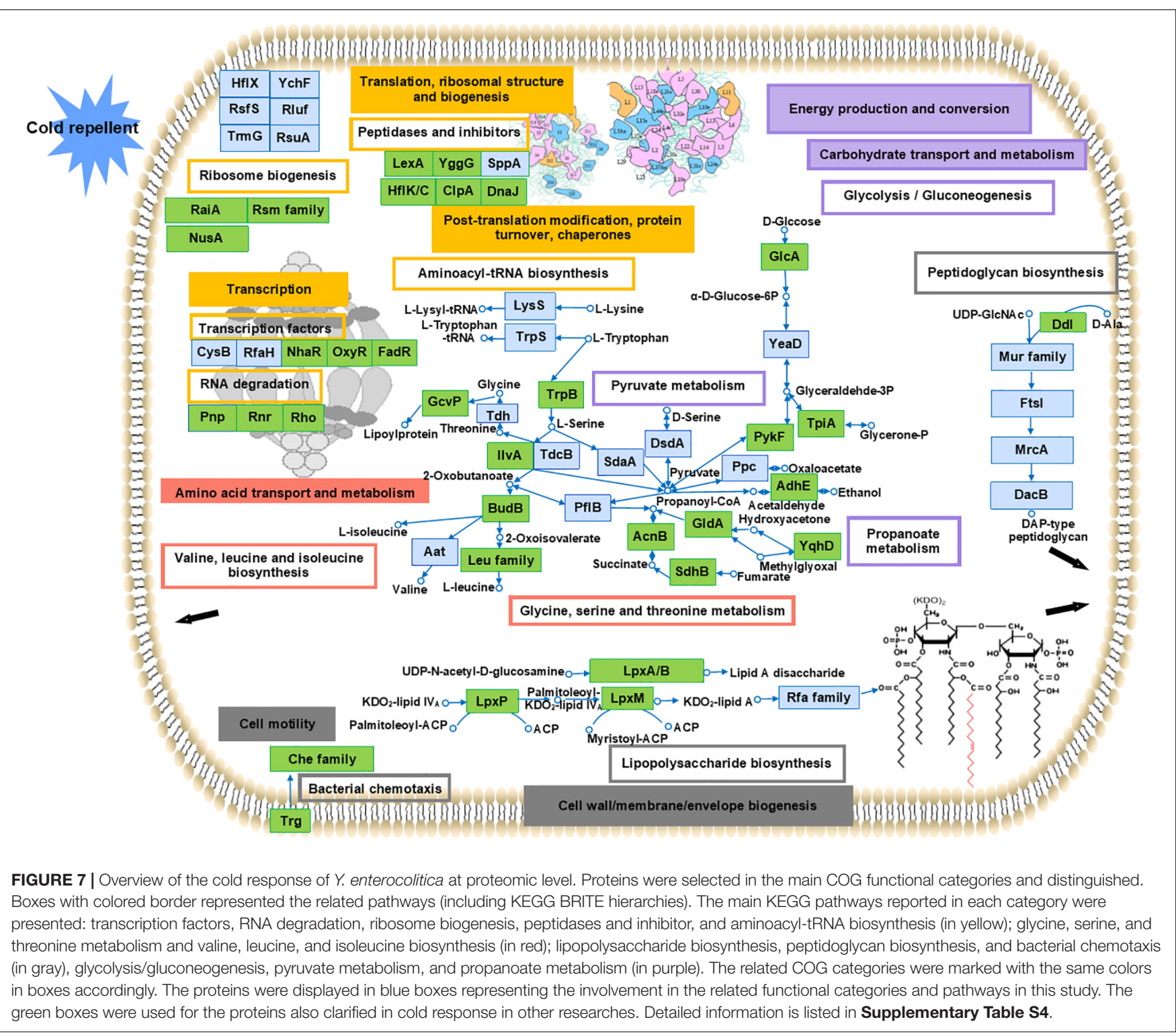


like ribosomal silencing factor RsfS, GTPase HflX, and ribosome-binding ATPase YchF under cold stress have not been clarified previously. Since some of them are involved in other stress response like heat, oxidative, and nutrient stress (Starosta et al., 2014; Hannemann et al., 2016; Dey et al., 2018), their potential roles under cold stress should be investigated. The proteins associated with peptidases and inhibitor such as LexA repressor, lipoprotein (encoded by yggG), and Protein HflK were induced under cold stress in this study. The cold-responsive function of these proteins was also found previously in other research (Phadtare and Inouye, 2004; Burakovsky et al., 2012; Jian et al., 2015). Besides, some transcription factors (encoded by $n h a R$, oxyR, fadR, $c y s B$, and $r f a H$ ) were also involved in regulation of cold response. Since the essential cold-responsive roles of these transcription factors (encoded by $n h a R, o x y R$, and $f a d R$ ) were investigated in E. coli (White-Ziegler et al., 2008), Vibrio vulnificus (Limthammahisorn et al., 2008), and Moraxella catarrhalis (Spaniol et al., 2013), transcription factors should also be focused on in $Y$. enterocolitica cold response.

A number of proteins involved in specific amino acids biosynthesis may reflect their importance in mediating survival under cold stress. In our research, the induced proteins participated in biosynthesis of various amino acids under cold stress (related COG categories shown in red boxes). These proteins are associated with the biosynthesis and metabolism of glycine, serine, and threonine (encoded by $\operatorname{trp} B, \operatorname{gcv} P$, ilvA, $t d h$, etc.), and valine, leucine, and isoleucine (encoded by leuA, leuB, leuC, leuD, budB, etc.). Similar amino acids have been demonstrated in previous studies to aid tolerance under cold stress conditions in many other bacteria (Fonseca et al., 2011; King et al., 2016).

Second, proteins associated with cell membrane and motility were identified (related COG categories shown in gray boxes). Certain proteins were identified in pathways, such as lipopolysaccharide biosynthesis (encoded by $\operatorname{lp} x A / B / P / M$ and $r f a C / Q$ ), peptidoglycan biosynthesis (encoded by murC/E, $d d l, d a c B$, etc.), and bacterial chemotaxis (encoded by $t r g$ and cheB/D/Z). The cold-responsive functions have been reported previously in many proteins mentioned in Supplementary Table S4. However, although the genes related to motility ( $f$ liS and YE2848) were detected in our transcriptional, the induction of them cannot be detected in our proteomic results. According to the proteomic data, almost all the proteins related to flagellar assembly were downregulated. The cold-responsive effect of flagella on cell motility at the protein level is unknown.

Meanwhile, valine, leucine, and isoleucine, as the branchedchain amino acids and the precursors for biosynthesis of isoand anteiso-branched-chain fatty acids, were utilized to regulate the membrane fluidity in response to cold in certain bacteria (Grau and de Mendoza, 1993; Annous et al., 1997; Klein et al., 1999). Levels of isoleucine and leucine significantly increase under cold stress in E. coli (Jozefczuk et al., 2010), and the expression of related genes (leuA/B/C/D and $i l v B / C / D / E / H)$ was also elevated in Thermoanaerobacter tengcongensis (Liu et al., 2014). Based on our proteomic results, the induction of leu $A / B / C / D$ encoding proteins was only detected in $44 \mathrm{~B}$, which implied the indispensable regulation of these branched-chain amino acids. However, the growth ability under cold stress of 44B was detected worse than II7D, which suggested that multiple pathways related to motility might be applied in cold response.

The considerable involvement of proteins has been detected and the transcriptional and physiological investigation associated with motility and fluidity contributes to our understanding of cold-response regulation of motility and membrane fluidity.

Additionally, certain pathways in energy production and conversion and carbohydrate transport and metabolism were also involved in this study (listed in Supplementary Table S4). The complex processes and pathways in cold response of $Y$. enterocolitica and the specific functions of other individual proteins predicted in the proteomic results are required to be investigated during cold adaptation.

This study demonstrates the strain-specific cold response of $Y$. enterocolitica at $4^{\circ} \mathrm{C}$, which is time-dependent, including cold acclimation and adaptation. The transcriptional analysis revealed the importance of the induction and repression of cold-shock genes in cold acclimation as well as the resumption of the non-cold shock genes in prolonged cold adaptation. Meanwhile, the time-dependent response at protein level was also found and the cold-responsive proteins identified in proteomic analysis were closely related to protein synthesis, cell membrane parts and cell motility. Additionally, the physiological processes in cell fluidity and motility might be responsible for differential growth abilities at low temperatures. By combining different approaches, cold response was described systematically, providing a better understanding of the significant physiological processes involved in cold stress of $Y$. enterocolitica.

\section{DATA AVAILABILITY STATEMENT}

All datasets generated for this study are included in the article and Supplementary Material.

\section{AUTHOR CONTRIBUTIONS}

CL contributed to designing, carrying out the experiment, and writing the manuscript. JM provided assistance for the proteome experiment and reviewed the manuscript. CT provided assistance for the experiment. TA reviewed the manuscript and gave advice. $\mathrm{CR}$ reviewed the manuscript.

\section{ACKNOWLEDGMENTS}

This study was financially supported by the Chinese Scholarship Council.

\section{SUPPLEMENTARY MATERIAL}

The Supplementary Material for this article can be found online at: https://www.frontiersin.org/articles/10.3389/fmicb.2019. 03037/full\#supplementary-material 


\section{REFERENCES}

Aguilar, P. S., Hernandez-Arriaga, A. M., Cybulski, L. E., Erazo, A. C., and de Mendoza, D. (2001). Molecular basis of thermosensing: a two-component signal transduction thermometer in Bacillus subtilis. EMBO J. 20, 1681-1691. doi: 10.1093/emboj/20.7.1681

Albanesi, D., Mansilla, M. C., and de Mendoza, D. (2004). The membrane fluidity sensor desk of Bacillus subtilis controls the signal decay of its cognate response regulator. J. Bacteriol. 186, 2655-2663. doi: 10.1128/jb.186.9.2655-2663.2004

Amin, M. K., and Draughon, F. A. (1987). Growth-characteristics of Yersiniaenterocolitica in pasteurized skim milk. J. Food Protect. 50, 849-852. doi: 10. 4315/0362-028x-50.10.849

Annous, B. A., Becker, L. A., Bayles, D. O., Labeda, D. P., and Wilkinson, B. J. (1997). Critical role of anteiso-C15: 0 fatty acid in the growth of Listeria monocytogenes at low temperatures. Appl. Environ. Microbiol. 63, 3887-3894.

Aricha, B., Fishov, I., Cohen, Z., Sikron, N., Pesakhov, S., Khozin-Goldberg, I., et al. (2004). Differences in membrane fluidity and fatty acid composition between phenotypic variants of Streptococcus pneumoniae. J. Bacteriol. 186, 4638-4644. doi: 10.1128/Jb.186.14.4638-4644.2004

Asadishad, B., Ghoshal, S., and Tufenkji, N. (2013). Role of cold climate and freeze-thaw on the survival, transport, and virulence of Yersinia enterocolitica. Environ. Sci. Technol. 47, 14169-14177. doi: 10.1021/es403726u

Bari, M. L., Hossain, M. A., Isshiki, K., and Ukuku, D. (2011). Behavior of Yersinia enterocolitica in foods. J. Pathog. 2011:420732. doi: 10.4061/2011/420732

Barria, C., Malecki, M., and Arraiano, C. M. (2013). Bacterial adaptation to cold. Microbiology 159, 2437-2443. doi: 10.1099/mic.0.052209-0

Begic, S., and Worobec, E. A. (2006). Regulation of Serratia marcescens ompF and ompC porin genes in response to osmotic stress, salicylate, temperature and $\mathrm{pH}$. Microbiology 152(Pt 2), 485-491. doi: 10.1099/mic.0.28428-0

Belosludtsev, K., Belosludtseva, N., Kondratyev, M., Agafonov, A., and Purtov, Y. (2014). Interaction of phospholipase A of the E. coli outer membrane with the inhibitors of eucaryotic phospholipases $\mathrm{A}(2)$ and their effect on the Ca2+induced permeabilization of the bacterial membrane. J. Membr. Biol. 247, 281-288. doi: 10.1007/s00232-014-9633-4

Benembarek, P. K. (1994). Presence, detection and growth of Listeriamonocytogenes in Seafoods - a review. Int. J. Food Microbiol. 23, 17-34. doi: 10.1016/0168-1605(94)90219-4

Berger, F., Morellet, N., Menu, F., and Potier, P. (1996). Cold shock and cold acclimation proteins in the psychrotrophic bacterium Arthrobacter globiformis SI55. J. Bacteriol. 178, 2999-3007. doi: 10.1128/jb.178.11.2999-3007.1996

Blomberg, P., Wagner, E. G., and Nordström, K. (1990). Control Of Replication Of Plasmid R1: the duplex between the antisense RNA, CopA, and its target, CopT, is processed specifically in vivo and in vitro by RNase III. EMBO J. 9, 2331-2340. doi: 10.1002/j.1460-2075.1990.tb07405.x

Bresolin, G., Neuhaus, K., Scherer, S., and Fuchs, T. M. (2006). Transcriptional analysis of long-term adaptation of Yersinia enterocolitica to low-temperature growth. J. Bacteriol. 188, 2945-2958. doi: 10.1128/JB.188.8.2945-2958.2006

Bresolin, G., Trcek, J., Scherer, S., and Fuchs, T. M. (2008). Presence of a functional flagellar cluster Flag-2 and low-temperature expression of flagellar genes in Yersinia enterocolitica W22703. Microbiology 154(Pt 1), 196-206. doi: 10.1099/ mic.0.2007/008458-0

Briani, F., Carzaniga, T., and Deho, G. (2016). Regulation and functions of bacterial PNPase. Wiley Interdiscip. Rev. RNA 7, 241-258. doi: 10.1002/wrna.1328

Burakovsky, D. E., Prokhorova, I. V., Sergiev, P. V., Milon, P., Sergeeva, O. V., Bogdanov, A. A., et al. (2012). Impact of methylations of $\mathrm{m} 2 \mathrm{G} 966 / \mathrm{m} 5 \mathrm{C} 967$ in 16S rRNA on bacterial fitness and translation initiation. Nucleic Acids Res. 40, 7885-7895. doi: 10.1093/nar/gks508

Burkart, M., Toguchi, A., and Harshey, R. M. (1998). The chemotaxis system, but not chemotaxis, is essential for swarming motility in Escherichia coli. Proc. Natl. Acad. Sci. U. S. A. 95, 2568-2573. doi: 10.1073/pnas.95.5.2568

Cacace, G., Mazzeo, M. F., Sorrentino, A., Spada, V., Malorni, A., and Siciliano, R. A. (2010). Proteomics for the elucidation of cold adaptation mechanisms in Listeria monocytogenes. J. Proteomics 73, 2021-2030. doi: 10.1016/j.jprot.2010. 06.011

Cao-Hoang, L., Dumont, F., Marechal, P. A., and Gervais, P. (2010). Inactivation of Escherichia coli and Lactobacillus plantarum in relation to membrane permeabilization due to rapid chilling followed by cold storage. Arch. Microbiol. 192, 299-305. doi: 10.1007/s00203-010-0555-y
Carty, S. M., Sreekumar, K. R., and Raetz, C. R. H. (1999). Effect of cold shock on lipid A biosynthesis in Escherichia coli. Induction at 12 degrees $\mathrm{C}$ of an acyltransferase specific for palmitoleoyl-acyl carrier protein. J. Biol. Chem. 274, 9677-9685. doi: 10.1074/jbc.274.14.9677

Coburn, G. A., and Mackie, G. A. (1998). Degradation of mRNA in Escherichia coli: an old problem with some new twists. Prog. Nucleic Acid Res. Mol. Biol. 62, 55-108. doi: 10.1016/s0079-6603(08)60505-x

Cordin, O., Banroques, J., Tanner, N. K., and Linder, P. (2006). The DEAD-box protein family of RNA helicases. Gene 367, 17-37. doi: 10.1016/j.gene.2005. 10.019

Dekker, N. (2000). Outer-membrane phospholipase A: known structure, unknown biological function. Mol. Microbiol. 35, 711-717. doi: 10.1046/j.1365-2958.2000. 01775.x

Delumeau, O., Lecointe, F., Muntel, J., Guillot, A., Guédon, E., Monnet, V., et al. (2011). The dynamic protein partnership of RNA polymerase inBacillus subtilis. Proteomics 11, 2992-3001. doi: 10.1002/pmic.201000790

Dey, S., Biswas, C., and Sengupta, J. (2018). The universally conserved GTPase HflX is an RNA helicase that restores heat-damaged $<\mathrm{em}>$ Escherichia col $i</ \mathrm{em}>$ ribosomes. J. Cell Biol. 217, 2519-2529. doi: 10.1083/jcb.201711131

Di Pietro, F., Brandi, A., Dzeladini, N., Fabbretti, A., Carzaniga, T., Piersimoni, L., et al. (2013). Role of the ribosome-associated protein PY in the cold-shock response of Escherichia coli. Microbiol. Open 2, 293-307. doi: 10.1002/mbo3.68

Divya, K. H., and Varadaraj, M. C. (2013). Behavioral pattern of native food isolates of Yersinia enterocolitica under simulated time-temperature combinations of the food chain. Food Nutr. Sci. 4, 365-375. doi: 10.4236/fns.2013.44047

Eberlein, C., Baumgarten, T., Starke, S., and Heipieper, H. J. (2018). Immediate response mechanisms of Gram-negative solvent-tolerant bacteria to cope with environmental stress: cis-trans isomerization of unsaturated fatty acids and outer membrane vesicle secretion. Appl. Microbiol. Biotechnol. 102, 2583-2593. doi: 10.1007/s00253-018-8832-9

Elhadad, D., Desai, P., Rahav, G., McClelland, M., and Gal-Mor, O. (2015). Flagellin is required for host cell invasion and normal Salmonella pathogenicity island 1 expression by Salmonella enterica serovar Paratyphi A. Infect. Immun. 83, 3355-3368. doi: 10.1128/IAI.00468-15

Ermolenko, D. N., and Makhatadze, G. I. (2002). Bacterial cold-shock proteins. Cell. Mol. Life Sci. 59, 1902-1913. doi: 10.1007/Pl00012513

European Food Safety Authority, and European Centre for Disease Prevention, and Control (2016). The European Union summary report on trends and sources of zoonoses, zoonotic agents and food-borne outbreaks in 2015. EFSA J. 14:4634.

Fonseca, P., Moreno, R., and Rojo, F. (2011). Growth of Pseudomonas putida at low temperature: global transcriptomic and proteomic analyses. Environ. Microbiol. Rep. 3, 329-339. doi: 10.1111/j.1758-2229.2010.00229.x

Galperin, M. Y., Makarova, K. S., Wolf, Y. I., and Koonin, E. V. (2014). Expanded microbial genome coverage and improved protein family annotation in the COG database. Nucleic Acids Res. 43, D261-D269. doi: 10.1093/nar/gku1223

Goverde, R. L. J., Huis in't Veld, J. H. J., Kusters, J. G., and Mooi, F. R. (1998). The psychrotrophic bacterium Yersinia enterocolitica requires expression of pnp, the gene for polynucleotide phosphorylase, for growth at low temperature $\left(5^{\circ} \mathrm{C}\right)$. Mol. Microbiol. 28, 555-569. doi: 10.1046/j.1365-2958.1998.00816.x

Grau, R., and de Mendoza, D. (1993). Regulation of the synthesis of unsaturated fatty acids by growth temperature in Bacillus subtilis. Mol. Microbiol. 8, 535542. doi: 10.1111/j.1365-2958.1993.tb01598.x

Greenwood, M. H., Coetzee, E. F., Ford, B. M., Gill, P., Hooper, W. L., Matthews, S. C., et al. (1985). The microbiology of cooked prawns and shrimps on retail sale. J. Hyg. 94, 319-326. doi: 10.1017/s0022172400061544

Hannemann, L., Suppanz, I., Ba, Q., MacInnes, K., Drepper, F., Warscheid, B., et al. (2016). Redox activation of the universally conserved ATPase YchF by Thioredoxin 1. Antioxid. Redox Signal. 24, 141-156. doi: 10.1089/ars.2015.6272

Hébraud, M., and Potier, P. (1999). Cold shock response and low temperature adaptation in psychrotrophic bacteria. J. Mol. Microbiol. Biotechnol. 1, 211-219.

Herbst, F.-A., Danielsen, H. N., Wimmer, R., Nielsen, P. H., and Dueholm, M. S. (2015). Label-free quantification reveals major proteomic changes in Pseudomonas putida F1 during the exponential growth phase. Proteomics 15, 3244-3252. doi: 10.1002/pmic.201400482

Horisaka, T., Fujita, K., Iwata, T., Nakadai, A., Okatani, A. T., Horikita, T., et al. (2004). Sensitive and specific detection of Yersinia pseudotuberculosis by loopmediated isothermal amplification. J. Clin. Microbiol. 42, 5349-5352. doi: 10. $1128 / \mathrm{Jcm} .42 .11 .5349-5352.2004$ 
Horn, G., Hofweber, R., Kremer, W., and Kalbitzer, H. R. (2007). Structure and function of bacterial cold shock proteins. Cell. Mol. Life Sci. 64, 1457. doi: 10.1007/s00018-007-6388-4

Hu, J., McCormick, R. J., Means, W. J., and Zhu, M. J. (2014). Polynucleotide phosphorylase is required for Escherichia coli O157:H7 growth above refrigerated temperature. Foodborne Pathog. Dis. 11, 177-185. doi: 10.1089/fpd. 2013.1632

Hussain, S., and Bernstein, H. D. (2018). The Bam complex catalyzes efficient insertion of bacterial outer membrane proteins into membrane vesicles of variable lipid composition. J. Biol. Chem. 293, 2959-2973. doi: 10.1074/jbc. RA117.000349

Iliev, M., and Najdenski, H. (2008). Monitoring of plasmid dissociation and pathogenic potential among Yersinia enterocolotica and Yersinia pseudotuberculosis during storage of refrigerated pork meat. Ann. Microbiol. 58, 623-632. doi: 10.1007/bf03175567

Jian, H., Xiong, L., He, Y., and Xiao, X. (2015). The regulatory function of LexA is temperature-dependent in the deep-sea bacterium Shewanella piezotolerans WP3. Front. Microbiol. 6:627. doi: 10.3389/fmicb.2015.00627

Jozefczuk, S., Klie, S., Catchpole, G., Szymanski, J., Cuadros-Inostroza, A., Steinhauser, D., et al. (2010). Metabolomic and transcriptomic stress response of Escherichia coli. Mol. Syst. Biol. 6:364. doi: 10.1038/msb.2010.18

Kanehisa, M., Furumichi, M., Tanabe, M., Sato, Y., and Morishima, K. (2016). KEGG: new perspectives on genomes, pathways, diseases and drugs. Nucleic Acids Res. 45, D353-D361. doi: 10.1093/nar/gkw1092

Kapatral, V., Olson, J. W., Pepe, J. C., Miller, V. L., and Minnich, S. A. (1996). Temperature-dependent regulation of Yersinia enterocolitica Class III flagellar genes. Mol. Microbiol. 19, 1061-1071. doi: 10.1046/j.1365-2958.1996.452978.x

King, T., Kocharunchitt, C., Gobius, K., Bowman, J. P., and Ross, T. (2016). Physiological response of Escherichia coli O157:H7 Sakai to dynamic changes in temperature and water activity as experienced during carcass chilling. Mol. Cell. Proteomics 15, 3331-3347. doi: 10.1074/mcp.M116.063065

Klein, W., Weber, M. H., and Marahiel, M. A. (1999). Cold shock response of Bacillus subtilis: isoleucine-dependent switch in the fatty acid branching pattern for membrane adaptation to low temperatures. J. Bacteriol. 181, 5341-5349.

Kocharunchitt, C., King, T., Gobius, K., Bowman, J. P., and Ross, T. (2014). Global genome response of Escherichia coli O157: H7 Sakai during dynamic changes in growth kinetics induced by an abrupt downshift in water activity. PLoS One 9:e90422. doi: 10.1371/journal.pone.0090422

Kumar, G., Hummel, K., Ahrens, M., Menanteau-Ledouble, S., Welch, T. J., Eisenacher, M., et al. (2016). Shotgun proteomic analysis of Yersinia ruckeri strains under normal and iron-limited conditions. Vet. Res. 47:100.

Limthammahisorn, S., Brady, Y. J., and Arias, C. R. (2008). Gene expression of cold shock and other stress-related genes in Vibrio vulnificus grown in pure culture under shellstock temperature control conditions. J. Food Prot. 71, 157-164. doi: $10.4315 / 0362-028 \mathrm{x}-71.1 .157$

Liu, B., Zhang, Y., and Zhang, W. (2014). RNA-Seq-based analysis of cold shock response in Thermoanaerobacter tengcongensis, a bacterium harboring a single cold shock protein encoding gene. PLoS One 9:e93289. doi: 10.1371/journal. pone.0093289

Macintyre, S., and Henning, U. (1990). The role of the mature part of secretory proteins in translocation across the plasma-membrane and in regulation of their synthesis in Escherichia-Coli. Biochimie 72, 157-167. doi: 10.1016/03009084(90)90141-3

Mathy, N., Jarrige, A. C., Robert-Le Meur, M., and Portier, C. (2001). Increased expression of Escherichia coli polynucleotide phosphorylase at low temperatures is linked to a decrease in the efficiency of autocontrol. J. Bacteriol. 183, 3848-3854. doi: 10.1128/JB.183.13.3848-3854.2001

Matos, R. G., Barbas, A., and Arraiano, C. M. (2009). RNase R mutants elucidate the catalysis of structured RNA: RNA-binding domains select the RNAs targeted for degradation. Biochem. J. 423, 291-301. doi: 10.1042/Bj20090839

Michaux, C., Holmqvist, E., Vasicek, E., Sharan, M., Barquist, L., Westermann, A. J., et al. (2017). RNA target profiles direct the discovery of virulence functions for the cold-shock proteins CspC and CspE. Proc. Natl. Acad. Sci. U.S.A. 114, 6824-6829. doi: 10.1073/pnas.1620772114

Michel, V., Lehoux, I., Depret, G., Anglade, P., Labadie, J., and Hebraud, M. (1997). The cold shock response of the psychrotrophic bacterium Pseudomonas fragi involves four low-molecular-mass nucleic acid binding proteins. J. Bacteriol. 179, 7331-7342. doi: 10.1128/jb.179.23.7331-7342.1997
Mukherjee, S., Babitzke, P., and Kearns, D. B. (2013). FliW and FliS function independently to control cytoplasmic flagellin levels in Bacillus subtilis. J. Bacteriol. 195, 297-306. doi: 10.1128/JB.01654-12

Mykytczuk, N., Trevors, J., Leduc, L., and Ferroni, G. (2007). Fluorescence polarization in studies of bacterial cytoplasmic membrane fluidity under environmental stress. Prog. Biophys. Mol. Biol. 95, 60-82. doi: 10.1016/j. pbiomolbio.2007.05.001

Neuhaus, K., Anastasov, N., Kaberdin, V., Francis, K. P., Miller, V. L., and Scherer, S. (2003). The AGUAAA motif in cspA1/A2 mRNA is important for adaptation of Yersinia enterocolitica to grow at low temperature. Mol. Microbiol. 50, 1629-1645. doi: 10.1046/j.1365-2958.2003.03795.x

Nikaido, H. (2003). Molecular basis of bacterial outer membrane permeability revisited. Microbiol. Mol. Biol. Rev. 67, 593-656. doi: 10.1128/mmbr.67.4.593656.2003

Onufryk, C., Crouch, M. L., Fang, F. C., and Gross, C. A. (2005). Characterization of six lipoproteins in the sigma(E) regulon. J. Bacteriol. 187, 4552-4561. doi: 10.1128/Jb.187.13.4552-4561.2005

Osterman, I. A., Dikhtyar, Y. Y., Bogdanov, A. A., Dontsova, O. A., and Sergiev, P. V. (2015). Regulation of flagellar gene expression in Bacteria. Biochemistry 80, 1447-1456. doi: 10.1134/S000629791511005X

Ostroff, S. M., Kapperud, G., Hutwagner, L. C., Nesbakken, T., Bean, N. H., Lassen, J., et al. (1994). Sources of sporadic Yersinia-enterocolitica infections in Norway - a prospective case-control study. Epidemiol. Infect. 112, 133-141. doi: $10.1017 / \mathrm{s} 0950268800057496$

Peixotto, S. S., Finne, G., Hanna, M. O., and Vanderzant, C. (1979). Presence, growth and survival of Yersinia-enterocolitica in oysters, shrimp and crab. J. Food Protect. 42, 974-981. doi: 10.4315/0362-028x-42.12.974

Phadtare, S. (2004). Recent developments in bacterial cold-shock response. Curr. Issues Mol. Biol. 6, 125-136.

Phadtare, S. (2011). Unwinding activity of cold shock proteins and RNA metabolism. RNA Biol. 8, 394-397. doi: 10.4161/rna.8.3.14823

Phadtare, S. (2012). Escherichia coli cold-shock gene profiles in response to over-expression/deletion of CsdA, RNase R and PNPase and relevance to lowtemperature RNA metabolism. Genes Cells 17, 850-874. doi: 10.1111/gtc. 12002

Phadtare, S., Alsina, J., and Inouye, M. (1999). Cold-shock response and coldshock proteins. Curr. Opin. Microbiol. 2, 175-180. doi: 10.1016/S1369-5274(99) 80031-9

Phadtare, S., and Inouye, M. (2004). Genome-wide transcriptional analysis of the cold shock response in wild-type and cold-sensitive, quadruple-csp-deletion strains of Escherichia coli. J. Bacteriol. 186, 7007-7014. doi: 10.1128/JB.186.20. 7007-7014.2004

Pieper, R., Huang, S. T., Clark, D. J., Robinson, J. M., Parmar, P. P., Alami, H., et al. (2008). Characterizing the dynamic nature of the Yersinia pestis periplasmic proteome in response to nutrient exhaustion and temperature change. Proteomics 8, 1442-1458. doi: 10.1002/pmic.200700923

Polissi, A., De Laurentis, W., Zangrossi, S., Briani, F., Longhi, V., Pesole, G., et al. (2003). Changes in Escherichia coli transcriptome during acclimatization at low temperature. Res. Microbiol. 154, 573-580. doi: 10.1016/S0923-2508(03)00 167-0

Ricke, S. C., Dawoud, T. M., Kim, S. A., Park, S. H., and Kwon, Y. M. (2018). Salmonella cold stress response: mechanisms and occurrence in foods. Adv. Appl. Microbiol. 104, 1-38. doi: 10.1016/bs.aambs.2018.03.001

Robins-Browne, R. M. (2013). "Chapter 14: Yersinia enterocolitica," in Food Microbiology: Fundamentals and Frontiers, 4th Edn, ed. L. B. M. Doyle, (Washington, DC: Amercian Society for Microbiology).

Robinson, J. A. (2019). Folded synthetic peptides and other molecules targeting outer membrane protein complexes in gram-negative bacteria. Front. Chem. 7:45. doi: 10.3389/fchem.2019.00045

Rollauer, S. E., Sooreshjani, M. A., Noinaj, N., and Buchanan, S. K. (2015). Outer membrane protein biogenesis in Gram-negative bacteria. Philos. Trans. R. Soc. B Biol. Sci. 370:20150023. doi: 10.1098/Rstb.2015.0023

Rudolph, J. D., and Cox, J. (2019). A network module for the perseus software for computational proteomics facilitates proteome interaction graph analysis. J. Proteome Res. 18, 2052-2064. doi: 10.1021/acs.jproteome.8b00927

Sklar, J. G., Wu, T., Gronenberg, L. S., Malinverni, J. C., Kahne, D., and Silhavy, T. J. (2007). Lipoprotein SmpA is a component of the YaeT complex that assembles outer membrane proteins in Escherichia coli. Proc. Natl. Acad. Sci. U.S.A. 104, 6400-6405. doi: 10.1073/pnas.0701579104 
Spaniol, V., Wyder, S., and Aebi, C. (2013). RNA-Seq-based analysis of the physiologic cold shock-induced changes in Moraxella catarrhalis gene expression. PLoS One 8:e68298. doi: 10.1371/journal.pone.006 8298

Starosta, A. L., Lassak, J., Jung, K., and Wilson, D. N. (2014). The bacterial translation stress response. FEMS Microbiol. Rev. 38, 1172-1201. doi: 10.1111/ 1574-6976.12083

Stefanopoulou, M., Kokoschka, M., Sheldrick, W. S., and Wolters, D. A. (2011). Cell response of Escherichia coli to cisplatin-induced stress. Proteomics 11, 4174-4188. doi: 10.1002/pmic.201100203

Storz, G., and Hengge, R. (2010). Bacterial Stress Responses. Washington, DC: American Society for Microbiology Press.

Tashiro, K., Kubokura, Y., Kato, Y., Kaneko, K.-I., and Ogawa, M. (1991). Survival of Yersinia enterocolitica in soil and water. J. Vet. Med. Sci. 53, 23-27. doi: 10.1292/jvms.53.23

Tatusov, R. L., Natale, D. A., Garkavtsev, I. V., Tatusova, T. A., Shankavaram, U. T., Rao, B. S., et al. (2001). The COG database: new developments in phylogenetic classification of proteins from complete genomes. Nucleic Acids Res. 29, 22-28. doi: 10.1093/nar/29.1.22

Townsend, M. K., Carr, N. J., Iyer, J. G., Horne, S. M., Gibbs, P. S., and Prüß, B. M. (2008). Pleiotropic phenotypes of a Yersinia enterocolitica flhD mutant include reduced lethality in a chicken embryo model. BMC Microbiol. 8:12. doi: 10.1186/ 1471-2180-8-12

Tudor, L., Togoe, I., Pop, A., and Mitranescu, E. (2008). The Yersinia enterocolitica species tolerance to temperature. Rom. Biotechnol. Lett. 13, 17-22. doi: 10.1089/ fpd.2009.0526

Tyanova, S., Temu, T., and Cox, J. (2016). The MaxQuant computational platform for mass spectrometry-based shotgun proteomics. Nat. Protoc. 11:2301. doi: 10.1038/nprot.2016.136

Vorachek-Warren, M. K., Carty, S. M., Lin, S., Cotter, R. J., and Raetz, C. R. (2002). An Escherichia coli mutant lacking the cold shock-induced palmitoleoyltransferase of lipid A biosynthesis: absence of unsaturated acyl chains and antibiotic hypersensitivity at 12 degrees C. J. Biol. Chem. 277, 14186-14193. doi: 10.1074/jbc.M200408200

Wang, X., Cui, Z., Jin, D., Tang, L., Xia, S., Wang, H., et al. (2009). Distribution of pathogenic Yersinia enterocolitica in China. Eur. J. Clin. Microbiol. Infect. Dis. 28, 1237-1244. doi: 10.1007/s10096-009-0773-x

Wareth, G., Eravci, M., Weise, C., Roesler, U., Melzer, F., Sprague, L. D., et al. (2016). Comprehensive identification of immunodominant proteins of Brucella abortus and Brucella melitensis using antibodies in the sera from naturally infected hosts. Int. J. Mol. Sci. 17:E659. doi: 10.3390/ijms1705 0659

Weber, M. H., and Marahiel, M. A. (2003). Bacterial cold shock responses. Sci. Prog. 86(Pt 1-2), 9-75. doi: 10.3184/003685003783238707

White-Ziegler, C. A., Um, S., Perez, N. M., Berns, A. L., Malhowski, A. J., and Young, S. (2008). Low temperature (23 degrees C) increases expression of biofilm-, cold-shock- and RpoS-dependent genes in Escherichia coli K-12. Microbiology 154(Pt 1), 148-166. doi: 10.1099/mic.0.2007/012021-0

Wollenweber, H. W., Schlecht, S., Lüderitz, O., and Rietschel, E. T. (1983). Fatty acid in lipopolysaccharides of Salmonella species grown at low temperature: identification and position. Eur. J. Biochem. 130, 167-171. doi: 10.1111/j.14321033.1983.tb07132.x

Wouters, J. A., Rombouts, F. M., Kuipers, O. P., De Vos, W. M., and Abee, T. (2000). The role of cold-shock proteins in low-temperature adaptation of food-related bacteria. Syst. Appl. Microbiol. 23, 165-173. doi: 10.1016/s07232020(00)80001-6

Wu, T., Malinverni, J., Ruiz, N., Kim, S., Silhavy, T. J., and Kahne, D. (2005). Identification of a multicomponent complex required for outer membrane biogenesis in Escherichia coli. Cell 121, 235-245. doi: 10.1016/j.cell.2005.02.015

Xu, S., Peng, Z., Cui, B., Wang, T., Song, Y., Zhang, L., et al. (2014). FliS modulates FlgM activity by acting as a non-canonical chaperone to control late flagellar gene expression, motility and biofilm formation in Yersinia pseudotuberculosis. Environ. Microbiol. 16, 1090-1104. doi: 10.1111/1462-2920.12222

Yamanaka, K., and Inouye, M. (2001). Selective mRNA degradation by polynucleotide phosphorylase in cold shock adaptation in Escherichia coli. J. Bacteriol. 183, 2808-2816. doi: 10.1128/Jb.183.9.2808-2816.2001

Yoon, Y., Lee, H., Lee, S., Kim, S., and Choi, K.-H. (2015). Membrane fluidityrelated adaptive response mechanisms of foodborne bacterial pathogens under environmental stresses. Food Res. Int. 72, 25-36. doi: 10.1016/j.foodres.2015. 03.016

Young, G. M., Smith, M. J., Minnich, S. A., and Miller, V. L. (1999). The Yersinia enterocolitica motility master regulatory operon, $\mathrm{flhDC}$, is required for flagellin production, swimming motility, and swarming motility. J. Bacteriol. 181, 28232833.

Zaritsky, A., Parola, A. H., Abdah, M., and Masalha, H. (1985). Homeoviscous adaptation, growth rate, and morphogenesis in bacteria. Biophys. J. 48, 337-339. doi: 10.1016/S0006-3495(85)83788-7

Zhao, X., Liu, Q., Xiao, K., Hu, Y., Liu, X., Li, Y., et al. (2016). Identification of the crp gene in avian Pasteurella multocida and evaluation of the effects of crp deletion on its phenotype, virulence and immunogenicity. BMC Microbiol. 16:125. doi: 10.1186/s12866-016-0739-y

Conflict of Interest: The authors declare that the research was conducted in the absence of any commercial or financial relationships that could be construed as a potential conflict of interest.

Copyright (c) 2020 Li, Murugaiyan, Thomas, Alter and Riedel. This is an open-access article distributed under the terms of the Creative Commons Attribution License (CC BY). The use, distribution or reproduction in other forums is permitted, provided the original author(s) and the copyright owner(s) are credited and that the original publication in this journal is cited, in accordance with accepted academic practice. No use, distribution or reproduction is permitted which does not comply with these terms. 